\title{
Effect of vascular resection for perihilar cholangiocarcinoma: A systematic review and meta-analysis
}

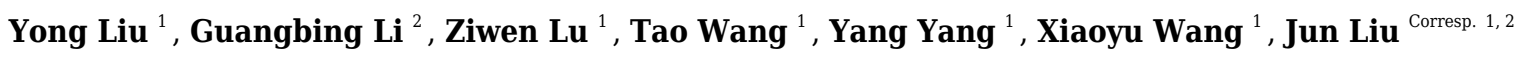 \\ ${ }^{1}$ Department of Liver Transplantation and Hepatobiliary Surgery, Shandong Provincial Hospital, Cheeloo College of Medicine, Shandong University, Jinan, \\ Shandong Province, China \\ 2 Department of Liver Transplantation and Hepatobiliary Surgery, Shandong Provincial Hospital Affiliated to Shandong First Medical University, Jinan, \\ Shandong Province, China \\ Corresponding Author: Jun Liu \\ Email address: dr_liujun1967@126.com
}

Objective: To evaluate the effect of vascular resection (VR), including portal vein resection (PVR) and hepatic artery resection (HAR), on short- and long-term outcomes in patients with perihilar cholangiocarcinoma (PHC).

Background: Resection surgery and transplantation are the main treatment methods for PHC that provide a chance of long-term survival. However, the efficacy and safety of VR, including PVR and HAR, for treating $\mathrm{PHC}$ remain controversial.

Methods: This study was registered at the International Prospective Register of Systematic Reviews (CRD42020223330). The EMBASE, PubMed, and Cochrane Library databases were used to search for eligible studies published through November 28, 2020. Studies comparing short- and long-term outcomes between patients who underwent hepatectomy with or without PVR and/or HAR were included. Randomand fixed-effects models were applied to assess the outcomes, including morbidity, mortality, and R0 resection rate, as well as the impact of PVR and HAR on long-term survival.

Results: Twenty-two studies including 4091 patients were deemed eligible and included in this study. The meta-analysis showed that PVR did not increase the postoperative morbidity rate (odds ratio (OR): $1.03,95 \%$ confidenceinterval $(\mathrm{Cl}): 0.74-1.42, \mathrm{P}=0.88)$ and slightly increased the postoperative mortality rate (OR: $1.61,95 \% \mathrm{Cl}: 1.02-2.54, \mathrm{P}=0.04$ ). HAR did not increase the postoperative morbidity rate (OR: $1.32,95 \% \mathrm{Cl}: 0.83-2.11, \mathrm{P}=0.24)$ and significantly increased the postoperative mortality rate (OR: 4.20, 95\% Cl: 1.88-9.39, P = 0.0005). Neither PVR nor HAR improved the R0 resection rate (OR: $0.70,95 \% \mathrm{Cl}$ : 0.47-1.03, P = 0.07; OR: 0.77, 95\% Cl: 0.37-1.61, $\mathrm{P}=0.49$, respectively) or long-term survival (OR: 0.52 , $95 \% \mathrm{Cl}: 0.35-0.76, \mathrm{P}=0.0008$; OR: $0.43,95 \% \mathrm{Cl}: 0.32-0.57, \mathrm{P}<0.00001$, respectively).

Conclusions: PVR is relatively safe and might benefit certain patients with advanced PHC in terms of long-term survival, but it is not routinely recommended. HAR results in a higher mortality rate and lower overall survival rate, with no proven benefit. 
1 Effect of vascular resection for perihilar cholangiocarcinoma: A systematic review and

2 meta-analysis

3

4

5 Yong Liu, MD ${ }^{1}$, Guangbing Li, MD ${ }^{2}$, Ziwen Lu, MSc ${ }^{1}$, Tao Wang, $\mathrm{MSc}^{1}$, Yang Yang MSc ${ }^{1}$,

6 Xiaoyu Wang, MSc ${ }^{1}$, Jun Liu, MD, $\mathrm{PhD}^{1,2^{*}}$

81 Department of Liver Transplantation and Hepatobiliary Surgery, Shandong Provincial

9 Hospital, Cheeloo College of Medicine, Shandong University, Jinan, Shandong Province,

10 250021, China

112 Department of Liver Transplantation and Hepatobiliary Surgery, Shandong Provincial Hospital

12 Affiliated to Shandong First Medical University, Jinan, Shandong, 250021, China

*Corresponding author: Jun Liu, MD, PhD, Professor, Department of Liver Transplantation and Hepatobiliary Surgery, Shandong Provincial Hospital, Cheeloo College of Medicine, Shandong University, Jinan, Shandong Province, 250021, China. Telephone: +86-531-68776932, Fax: +86-531-87925615, Email: dr_liujun1967@126.com. 


\section{Abstract}

24 Objective: To evaluate the effect of vascular resection (VR), including portal vein resection

(PVR) and hepatic artery resection (HAR), on short- and long-term outcomes in patients with perihilar cholangiocarcinoma $(\mathrm{PHC})$.

Background: Resection surgery and transplantation are the main treatment methods for PHC that provide a chance of long-term survival. However, the efficacy and safety of VR, including PVR and HAR, for treating PHC remain controversial.

Methods: This study was registered at the International Prospective Register of Systematic Reviews (CRD42020223330). The EMBASE, PubMed, and Cochrane Library databases were used to search for eligible studies published through November 28, 2020. Studies comparing short- and long-term outcomes between patients who underwent hepatectomy with or without PVR and/or HAR were included. Random- and fixed-effects models were applied to assess the outcomes, including morbidity, mortality, and R0 resection rate, as well as the impact of PVR and HAR on long-term survival.

Results: Twenty-two studies including 4091 patients were deemed eligible and included in this study. The meta-analysis showed that PVR did not increase the postoperative morbidity rate (odds ratio (OR): 1.03, 95\% confidence interval $(\mathrm{CI}): 0.74-1.42, \mathrm{P}=0.88$ ) and slightly increased the postoperative mortality rate $(\mathrm{OR}: 1.61,95 \% \mathrm{CI}: 1.02-2.54, \mathrm{P}=0.04)$. HAR did not increase

41 the postoperative morbidity rate (OR: $1.32,95 \% \mathrm{CI}: 0.83-2.11, \mathrm{P}=0.24)$ and significantly

42 increased the postoperative mortality rate (OR: $4.20,95 \% \mathrm{CI}: 1.88-9.39, \mathrm{P}=0.0005)$. Neither 
43 PVR nor HAR improved the R0 resection rate (OR: 0.70, 95\% CI: 0.47-1.03, P = 0.07; OR: 0.77,

44 95\% CI: 0.37-1.61, P = 0.49, respectively) or long-term survival (OR: 0.52, 95\% CI: 0.35-0.76, P

$45=0.0008$; OR: 0.43, 95\% CI: 0.32-0.57, P $<0.00001$, respectively).

46 Conclusions: PVR is relatively safe and might benefit certain patients with advanced PHC in

47 terms of long-term survival, but it is not routinely recommended. HAR results in a higher

48 mortality rate and lower overall survival rate, with no proven benefit.

\section{Introduction}

Cholangiocarcinoma is a rare adenocarcinoma that originates from the epithelial cells of

bile ducts. Perihilar cholangiocarcinoma (PHC) is the main type of cholangiocarcinoma,

accounting for $50 \%$ to $67 \%$ of cases (1-3). The prognosis of $\mathrm{PHC}$ is generally poor because of its

anatomical location and aggressive biology. Resection surgery and transplantation are the main

treatment methods for PHC that provide a chance of long-term survival (4). The median overall

survival (OS) of patients with PHC who undergo curative resection varies from 19 to 39 months

The objective of surgery is to achieve R0 resection. However, PHC usually adheres to or is

surrounded by vessels, such as the portal vein or hepatic artery, which makes curative resection difficult to achieve. Therefore, to achieve R0 resection, vascular resection (VR) can be performed during the operation. It has been reported that the proportion of VR during PHC surgery ranges from $15 \%$ to $38 \%(6-10)$. VR refers to portal vein resection (PVR), hepatic artery 
exists. For PVR, portal vein involvement by PHC was previously considered a sign of unresectability (11). With the development of surgical techniques, PVR has been performed at several clinical centers (12-14). However, the efficacy and safety of PVR for PHC are controversial. Ebata et al. (12) reported that combined portal vein and liver resection can offer long-term survival to some selected patients with advanced PHC. However, Hoffmann et al. (15) found that PVR greatly increased the perioperative morbidity rate and had no benefit for PHC in terms of the oncologic outcomes. In addition, surgical resection with simultaneous HAR for PHC is a demanding procedure $(13,16-18)$. Similar to PVR, attitudes toward HAR remain inconsistent. Miyazaki et al. (19) reported that HAR had no beneficial effect on prognosis and led to an increase in the perioperative morbidity and mortality rates; thus, the use of HAR may not be justified. Nagino et al. (20) demonstrated that major hepatectomy with HAR could offer a better chance of long-term survival in selected PHC patients.

To date, several meta-analyses have been performed to evaluate the efficacy and safety of VR for PHC patients; however, the results of these studies were inconsistent. By including 2457 patients, Abbas et al. (21) found that PVR may result in survival benefits for some patients with advanced PHC, which was similar to Chen's study (22). However, Wu et al. (23) and Yu et al. (24) found that PVR increases postoperative mortality and morbidity and worsens long-term survival; thus, surgical decisions should be made cautiously. For HAR, Abbas et al. (21) and Yu et al. (24) found that HAR is associated with increased mortality and morbidity without proven survival benefits for PHC patients. In a recent guideline for cholangiocarcinoma from Italy (25), PVR was recommended when there was unilateral portal vein invasion. However, the 
85

recommendation for PVR in this study was limited with a low quality of evidence due to the small number of related studies. Further, hardly any attention was given to HAR in the Italian study. Given these conflicting recommendations, the efficacy and safety of PVR and HAR for treating PHC patients need to be further clarified.

The aim of this study was to systematically review and statistically evaluate the effect of VR, including PVR and HAR, on short- and long-term outcomes in PHC patients.

\section{Materials and methods}

\section{Search strategy}

This meta-analysis was performed in accordance with the guidelines and review protocols of the Preferred Reporting Items for Systematic Reviews and Meta-analysis (PRISMA) statement (26). This study was registered at the International Prospective Register of Systematic Reviews (CRD42020223330). Two authors (Y.L. and G.B.L.) conducted a literature search independently using the EMBASE, PubMed, and Cochrane Library databases up to November 28, 2020. The search terms were "hilar cholangiocarcinoma", "Klatskin's tumour", "hepatectomy", "hepatic artery", "portal vein" and "vascular resection". Two authors (Y.L. and G.B.L.) independently reviewed the titles, abstracts and full texts for eligibility on the basis of predesigned inclusion and exclusion criteria. Disagreements were settled through consensus or by the judgment of a third author (Z.W.L). A description of the search strategy is shown in our evidence report (Supporting Table S2). To avoid omission of other studies that were not indexed, the reference lists of the included studies were also reviewed.

\section{Eligibility criteria}


The inclusion criteria were as follows: (1) humans were used as the research objects; (2)

107

108

109

110

111

112

113

114

115

116

117

118

119

120

121

122

123

124

125

126

full-text articles published in English; (3) all included subjects were diagnosed with PHC; and

(4) all enrolled patients underwent curative surgery, with or without resection of the portal vein

or hepatic artery. Records were excluded if they were classified as a case report or letter or if the

full text was not available. Studies with inadequate data were excluded. Studies including other

malignancies, such as gallbladder cancer, hepatic carcinoma or distal cholangiocarcinoma, were

also excluded. In the case of duplicate studies, the latest or most integrated data were chosen for analysis.

\section{Data extraction}

Two independent reviewers extracted the following attainable data from the included studies: first author, country, year of publication, inclusive period of study, number of patients, Bismuth-Corlette stage, intraoperative blood loss, 90-day mortality, total morbidity, staging of Union for International Cancer Control Unites (UICC), vascular invasion rate, lymph node metastasis rate, median survival time, 1-, 3-, and 5-year OS, 1-, 3-, and 5-year disease-free survival (DFS), and hazard ratios (HRs) with 95\% confidence intervals (CIs) for OS. HRs were obtained in two ways: (1) acquired directly from the article or (2) obtained from Kaplan-Meier survival curves following the methods reported by Tierney et al. (27) and using Engauge

Digitizer version 4.1 (SourceForge, Boston, USA).

\section{Quality assessment}

The study quality was assessed using the 9-score system of the Newcastle-Ottawa Scale (NOS) (28). The assessment was based on three aspects: (I) selection; (II) comparability; and 
127 (III) outcome. A follow-up duration of at least 2 years was considered adequate. The score

128 provides an assessment of bias for the included studies.

129

130

131

132

133

134

135

136

137

138

139

140

141

142

143

144

145

146

147

\section{Statistical analysis}

The primary purpose of this study was to evaluate the effect of PVR and HAR on long-term outcomes in PHC patients, and the statistical indicators included 1-, 3-, and 5-year OS and 1-, 3-, and 5-year DFS. The secondary purpose of this study was to evaluate the safety of PVR and HAR for PHC patients, and the statistical indicators included 90-day mortality, overall morbidity and the posthepatectomy liver insufficiency (PHI) rate. The 90-day mortality rate included the number of patients who died within 90 days after surgery but excluded the number of patients who died during the operation. Overall morbidity was recorded according to the types of postoperative complications, including intra-abdominal abscess, PHI, bile leakage, vascular complications, etc. (29). Since there was no uniform definition of PHI in the included studies, the PHI rate could only be determined based on individual study reports.

Dichotomous categorical variables were analyzed using the Mantel-Haenszel test.

Continuous categorical variables were analyzed using the inverse variance test. The results were expressed using forest plots and presented as odds ratios (ORs) and mean differences (MDs) and 95\% CIs. Heterogeneity among studies was assessed using the Cochrane Q-test and P-value.

Statistically significant heterogeneity was defined as $\mathrm{I}^{2}>50 \%$ or a chi-squared P-value $<0.1$. When heterogeneity was significant, a random-effects model was applied; otherwise, a fixedeffects model was used. A "leave-one-out" sensitivity analysis was conducted to identify the source of heterogeneity when significant heterogeneity was present. Funnel plots were used to 
148

150

151

152

153

evaluate the presence of significant publication bias.

The data syntheses in this meta-analysis were performed using RevMan 5.4 and R software (version 4.0.3). A two-sided $\mathrm{P}<0.05$ was deemed to indicate statistical significance.

\section{Results}

\section{Literature search}

As shown in Figure 1, 1693 records were incipiently included in our search. After the removal of duplicate publications, 1174 studies remained for title and abstract screening, and 642 records and 422 records were excluded based on title reading and abstract screening, respectively. Subsequently, 110 full texts were assessed for eligibility. Among them, 88 records were further excluded for the following reasons: not in English $(\mathrm{n}=7)$; abstract form only $(\mathrm{n}=$ $38)$; contained other malignancies or benign tumors $(n=2)$; reconstruction or no reconstruction as comparison item $(n=2)$; inadequate data $(n=7)$; and case reports $(n=32)$. Finally, 22 studies (6-10, 16, 19, 20, 30-43) including 4091 PHC patients were eligible for this systematic review and meta-analysis.

\section{Study characteristics}

Study level characteristics are shown in Table 1. All studies were cohort studies published between 1997 and 2020. The total number of patients enrolled was 4,091, and the sample capacities of these studies ranged from 28 to 787 patients. In this meta-analysis, the rates of PVR during curative surgery for $\mathrm{PHC}$ varied from $11 \%$ to $73 \%$, with an average rate of $27 \%(6-10,16$, 19, 20, 30-43). Compared to PVR, HAR was relatively rare and performed in only $10 \%$ of all enrolled patients. 
169

170

171

172

173

174

175

176

177

178

179

180

181

182

183

184

185

186

187

188

189

\section{0-day mortality}

Eleven studies provided data on 90 -day mortality $(6,9,10,19,30,31,34,39,41-43)$. The

meta-analysis indicated that VR could increase postoperative mortality (OR: $1.66,95 \%$ CI: 1.11 -

2.48, $\mathrm{P}=0.01$ ) (Fig. 2A). A significant difference also existed between the PHC patients with

and without PVR, and the pooled OR $(95 \% \mathrm{CI})$ was $1.61(1.02,2.54)$, with $\mathrm{P}=0.04$ (Fig. 2B).

For patients with and without HAR, the pooled result showed significantly higher mortality

among patients who underwent HAR (OR: 4.20, 95\% CI: 1.88-9.39, $\mathrm{P}=0.0005)$ (Fig. 2C).

\section{Overall morbidity}

Eleven studies containing 2189 patients provided data on overall morbidity $(7-10,16,19$,

$32,39,41-43)$. The meta-analysis indicated no difference in morbidity between the patients with and without VR (OR: 1.04, 95\% CI: 0.86-1.26, $\mathrm{P}=0.68)$ (Fig. 3A). A similar result was also found when comparing overall morbidity between patients with and without PVR (OR: 1.03, 95\% CI: 0.74-1.42, $\mathrm{P}=0.88$ ) (Fig. 3B). Furthermore, the meta-analysis indicated that HAR did not increase postoperative morbidity (OR: 1.32, 95\% CI: 0.83-2.11, $\mathrm{P}=0.24)$ (Fig. 3C).

\section{Posthepatectomy liver insufficiency}

To further explore the impact of VR on PHI, we analyzed this complication alone. Ten studies provided data on PHI $(7,8,10,16,31,32,34,39,42,43)$. The meta-analysis indicated a significantly higher PHI rate among patients with VR (OR: 1.77, 95\% CI: 1.37-2.28, P < 0.00001) (Fig. 4A). A similar result was obtained when comparing the PHI rate between patients with and without PVR (OR: 1.60, 95\% CI: 1.19-2.16, P =0.002) (Fig. 4B). For patients with and without HAR, the pooled result showed a significantly higher PHI rate among patients who 
190

191

192

193

194

195

196

197

198

199

200

201

202

203

204

205

206

underwent HAR (OR: 1.77, 95\% CI: 1.23-2.54, $\mathrm{P}=0.002)($ Fig. 4C).

\section{R0 margin status}

Twelve studies containing 2294 patients reported the difference in the R0 margin status (6$9,16,30-32,34,36,39,42)$. The meta-analysis indicated no difference in the $\mathrm{R} 0$ resection rate between patients with and without VR (OR: 0.71, 95\% CI: 0.50-1.01, P = 0.06) (Fig. 5A). The analysis between patients with and without PVR showed no statistically significant difference (OR: $0.70,95 \%$ CI: $0.47-1.03, \mathrm{P}=0.07$ ) (Fig. 5B). For patients with and without HAR, the metaanalysis demonstrated a similar outcome (OR: 0.77, 95\% CI: 0.37-1.61, $\mathrm{P}=0.49)$ (Fig. 5C).

\section{Long-term survival}

Eighteen studies provided data on 1-, 3-, and 5-year OS and DFS $(7-10,16,19,20,31,32$, 34-37, 39-43). The pooled results are shown in Table 2 . The pooled analysis showed that patients with VR had worse long-term survival. The meta-analysis showed that the 3- and 5-year OS rates were significantly lower in patients with VR than in those without VR $(\mathrm{P}<0.00001)$, while the 1-year OS was not statistically significant different (OR: $0.94,95 \%$ CI: $0.54-1.64, \mathrm{P}=0.83$ ). In addition, compared with those without PVR, patients with PVR had worse long-term survival (1year OS: OR: $0.77,95 \%$ CI: $0.49-1.20, \mathrm{P}=0.25$; 3-year OS: OR: $0.45,95 \%$ CI: $0.36-0.57, \mathrm{P}<$ 0.00001; 5-year OS: OR: $0.52,95 \% \mathrm{CI}: 0.35-0.76, \mathrm{P}=0.0008$ ). For patients with and without HAR, the pooled result showed significantly worse long-term survival among patients who underwent HAR (1-year OS: OR: 0.64, 95\% CI: 0.11-3.69, P = 0.62; 3-year OS: OR: 0.55, 95\% CI: 0.41-0.74, P < 0.0001; 5-year OS: OR: 0.43, 95\% CI: 0.32-0.57, $\mathrm{P}<0.00001)$. Meanwhile, there was no difference in the 1-, 3-, or 5-year DFS between patients with and without VR (OR: 
212 0.42-2.35, $\mathrm{P}=0.98)$. Furthermore, eight studies provided data on the HR for OS $(7,8,20,30,35$,

$21337,40,42)$. The pooled analysis indicated that VR was relevant to a shorter OS (HR: 1.44, 95\%

214 CI: 1.25-1.67, P < 0.001) (Fig. 6A).

215 Intraoperative blood loss

216 Eight included studies provided data on intraoperative blood loss $(7,9,16,19,31,39,42$,

217 43), and the mean volume of blood loss was significantly greater when VR was performed (MD

$218=433.66,95 \%$ CI: 91.69-775.63, $\mathrm{P}=0.01)($ Fig. 6B).

219 UICC staging

Five studies provided data on UICC staging $(8,9,32,34,42)$. The proportion of patients diagnosed at UICC stage T3-T4 ranged from $48 \%$ to $100 \%$ and from $15 \%$ to $51 \%$ in patients with and without VR, respectively. The meta-analysis indicated a higher UICC staging among patients with VR (OR: 4.72, 95\% CI: 1.05-21.12, $\mathrm{P}=0.04)$ (Fig. 6C).

\section{Vascular invasion}

Vascular invasion was reported in eight studies $(9,10,19,30,32,34,39,42)$, and the

positive invasion rate ranged from $31 \%$ to $88 \%$ and from $0 \%$ to $86 \%$ in patients with and without

VR, respectively. The mean vascular invasion rate was $39 \%$ in patients without VR, $85 \%$ in patients with PVR, and 49\% in patients without HAR. Patients who underwent VR had a higher vascular invasion rate (OR: 2.31, 95\% CI: 1.70-3.13, P < 0.00001) (Fig. 6D).

\section{Lymph node metastasis}

Lymph node metastasis was reported in ten of the included studies $(10,16,19,31,32,34$, 
232 39-42). The mean lymph node metastasis rates in patients with and without VR were 55.5\% and

$23335.8 \%$, respectively. The mean lymph node metastasis rates in patients with PVR and HAR were

$23452.1 \%$ and 62.2\%, respectively. As shown in Fig. 7A-7C, the meta-analyses revealed that

235 patients with VR, either PVR or HAR, had a higher lymph node metastasis rate than those

236 without VR (OR: 2.20, 95\% CI: 1.80-2.69, P < 0.00001; OR: 2.07, 95\% CI: 1.64-2.61, P <

237 0.00001; OR: 2.68, 95\% CI: 1.95-3.68, P < 0.00001, respectively).

238

239

240

241

242

\section{Discussion}

$\mathrm{PHC}$ is a rare malignancy that accounts for less than $2 \%$ of total human malignancies (44).

The tumor often invades the bile duct through the wall and extends to the periductal tissues and adjacent structures (45). Given the anatomical location and aggressive biological characteristics of PHC, most PHC patients are in advanced stages when examined. In fact, despite the use of various imaging tests to assess the tumor status, 40-50\% of PHC patients are found to have unresectable tumors during the operation $(46,47)$. Among them, involvement of the main portal vein, bilateral portal vein and/or hepatic artery branches are important reasons for the unresectability of tumors (46).

Surgical resection for PHC is highly technically demanding and could be challenging for hepatobiliary surgeons (48). Due to the changes in surgical philosophy and other aspects, radical surgery for PHC has also undergone great changes. Currently, curative surgery for PHC includes major hepatectomy, bile duct excision, locoregional lymph node dissection, and combined caudate lobectomy $(38,49,50)$. Due to local anatomical considerations, vascular invasion is not uncommon in PHC. According to the included studies, the rate of vascular invasion confirmed 
253 by histology ranges from $20 \%$ to $87 \%(9,10,19,30,32,34,39,42)$. Furthermore, when the

254 vessel can be reconstructed after resection, vascular invasion is no longer an absolute

255 contraindication for PHC surgery. However, while VR (including PVR and HAR) has been

256 performed at many clinical centers, their effect in patients with PHC remains controversial, and

257 previous comparative studies have reported inconsistent results $(19,30,38,49,51-53)$.

258 Due to the complexity of biliary and hepatic resection, the postoperative morbidity rate for

259 PHC is significant, ranging from $36 \%$ to $81 \%(7-10,16,19,32,41-43)$. This meta-analysis

260 showed that neither PVR nor HAR increased the incidence of postoperative complications (all P

$261>0.05)$. PHI seriously affects the patient's recovery and prognosis. The meta-analysis indicated

262 that patients with PVR had a significantly higher incidence of PHI, and a similar result could be

263 found when comparing patients with and without HAR. The reasons for these findings are that

264 PVR and/or HAR may prolong the period of liver ischemia during vascular reconstruction,

265 which may aggravate ischemic damage to the remnant liver (54). To reduce the incidence of PHI,

266 preoperative portal vein embolization (PVE), which was first proposed by Kinoshita et al. (55)

267 and Makuuchi et al. (56) in the 1980s, has been widely performed in many centers before surgery

268 for PHC.

269 Whether PVR increases postoperative mortality remains controversial. The portal vein

bifurcation lies directly posterior to the hepatic duct confluence and therefore frequently shows

tumor involvement. To achieve R0 resection, curative surgery might therefore require

concomitant resection of the portal vein bifurcation. Most studies have indicated that patients

with PVR have a higher mortality rate than those without PVR, ranging from $0 \%$ to $19 \%$ and

Peer] reviewing PDF | (2021:04:60471:2:0:NEW 22 Aug 2021) 
274 from $0 \%$ to $16 \%$, respectively $(6,7,19,30,31,34,39,41,43)$, but other studies have shown

275 inconsistent results. In 2014, Tamoto et al. (42) reported 0\% mortality in patients with PVR and

$27615 \%$ mortality in patients without PVR, which was similar to She's study (9). This meta-analysis

277 showed that PVR might increase mortality. However, the mean mortality rate was $4.0 \%$ in

278 patients without PVR and 6.2\% in patients with PVR. These results showed that although PVR

279 increased mortality, it was to an acceptable level. Compared to PVR, the effect of HAR on

mortality was similar. All five included studies showed that patients with HAR had a higher

mortality rate than those without HAR. The meta-analysis showed that HAR greatly increased

mortality $(\mathrm{P}=0.0005)$. The mean mortality rate was $1.7 \%$ in patients without HAR and $5.4 \%$ in

patients with HAR. Consequently, it seems that HAR is more likely to significantly increase

mortality.

The resection margin is a vital prognostic factor for PHC surgery. In most surgical series

that have included patients treated with hepatectomy combined with extrahepatic biliary

resection, an R0 margin was obtained in $55-90 \%$ of patients $(6-9,16,30-32,34,36,39,42)$.

Although R1 resection has shown some benefit to survival when compared to nonoperative

treatment, R0 margins should be achieved as far as possible (57-59). This meta-analysis showed

no difference in the $\mathrm{R} 0$ resection rate between patients with and without PVR, and a similar

result could be found when comparing patients with and without HAR. The mean R0 resection

rates were $76 \%, 69 \%$ and $70 \%$ in patients without VR, with HAR and with PVR, respectively.

Although patients with VR had disease of a more advanced stage, the validity of VR in terms of 
295

296

297

298

299

300

301

302

303

304

305

306

307

308

309

310

311

312

313

314

315

previous studies, we seem to be able to conclude that VR (including PVR and HAR) can achieve

a higher $\mathrm{R} 0$ resection rate because these patients can only achieve $\mathrm{R} 1$ resection or even $\mathrm{R} 2$

resection if VR is not performed. Of course, this conclusion needs to be further verified.

The results of the survival analysis showed that patients with PVR had poorer OS than those

without VR, although the 1-year OS was not statistically significant different. These results seem

to imply that the surgical oncologic outcome of patients with PVR is worse than that of patients

without PVR. However, subsequent analysis found that patients with PVR had more advanced

disease and higher positive lymph node metastasis, both of which are adverse prognostic factors

(60). Furthermore, some studies have shown that patients with PVR have a significant survival

advantage over unresectable patients $(9,20,32)$. Considering that PVR did not increase the

postoperative morbidity rate and slightly increased the mortality rate, it seems that PVR is

acceptable for selected patients. At present, there is no uniform conclusion on the selection of

suitable patients for PVR. The invasion of both portal branches strongly contraindicates hepatic

resection and this has been sustained by different guidelines (61-63). In addition, patients with

distant metastatic disease or involvement of aortocaval or truncal nodes are unlikely to benefit

from resection (64). Therefore, we suggest that PVR could be performed in PHC patients with a

preoperative or intraoperative finding of unilateral portal vein invasion and without a distant

metastatic event. Besides, considering the increased incidence of PHI associated with PVR,

surgical decision should be made cautiously according to the physical condition of patients.

However, the meta-analysis showed that HAR did not increase postoperative morbidity and

achieved an acceptable R0 resection rate but significantly increased postoperative mortality.

Peer] reviewing PDF | (2021:04:60471:2:0:NEW 22 Aug 2021) 
316 Meanwhile, for long-term survival, the 1-, 3-, and 5-year OS rates in patients with HAR were

$31759.57 \%, 43.90 \%$ and $27.81 \%$, respectively, and $64.71 \%, 54.12 \%$ and $46.75 \%$ in patients without

318 HAR, respectively. These results showed that HAR has not been demonstrated to benefit PHC

319 patients in terms of safety and long-term survival.

320 High heterogeneity was found in the analysis of several covariates, especially R0 margin

321

322

323

324

325

326

328

331

332 status $\left(\mathrm{I}^{2}=70, \mathrm{P}=0.009\right)$, intraoperative blood loss $\left(\mathrm{I}^{2}=89 \%, \mathrm{P}<0.00001\right)$ and UICC staging $\left(\mathrm{I}^{2}=85 \%, \mathrm{P}<0.0001\right)$. For R0 margin status, through a "leave-one-out" sensitivity analysis, we found that one study (7) may have contributed to the heterogeneity. In Mizuno's study, patients without VR had earlier tumor statuses, with a significantly lower proportion of T4 stage patients than those with VR (either PVR or HAR), at $25 \%$ versus $85 \%$, respectively. Therefore, the R0 resection rate in patients without VR was markedly higher than in those with VR, either PVR or HAR $(84.7 \%, 68.8 \%$ and $63.7 \%$, respectively). Moreover, the sample size of the study was extremely large, and therefore the effect on heterogeneity was large. After removing Mizuno's study, similar results were obtained that neither PVR nor HAR improved the R0 resection rate. In addition, for the high heterogeneity found in the analysis of intraoperative blood loss, the possible reasons were as follows: 1) the year of publication of the included studies ranged from 1997 to 2020, and advances in surgical techniques across this relatively long period could lead to large differences in intraoperative parameters, such as intrahepatic blood loss; 2) surgical experience varies among clinical centers, and intraoperative blood loss thus varies among different centers; and 3) although all PHC patients underwent hepatectomy, the extent of liver resection varied depending on the location of the tumor, thus resulting in a difference in 
337

338

339

340

341

342

343

344

345

346

347

348

349

350

351

352

353

354

355

356

357

intraoperative blood loss. Likewise, for the obvious heterogeneity found in the analysis of UICC

staging, after checking the details, we found that two studies $(8,32)$ may have contributed to the

heterogeneity. In these studies, a much higher proportion of patients with VR were diagnosed at

UICC stage T3-T4.

This review has several limitations that should be mentioned. First, there were no

randomized trials on this topic, and all eligible studies were observational studies. Second, a

large number of studies were excluded due to either inadequate data or the lack of an effective

comparison group. Third, data were missing in a few of the included studies, and the statistical

power was relatively low. Last, the retrospective study design has inherent limitations, and

inherent information bias in the original studies can always cause problems.

\section{Conclusions}

In conclusion, $\mathrm{PHC}$ is an uncommon and aggressive disease with a poor long-term prognosis. PVR is relatively safe and might confer benefits to certain patients with advanced PHC in terms of long-term survival. HAR is related to increased mortality and has not been demonstrated to benefit long-term survival, which should be considered before performing this procedure. Data from randomized controlled trials are required to further prove the findings in this study.

Acknowledgement: The authors thank American Journal Experts for language editing.

\section{References}

1. Nakeeb A, Pitt H, Sohn T, Coleman J, Abrams R, Piantadosi S, Hruban R, Lillemoe K, Yeo C, Cameron J. 
358 Cholangiocarcinoma. A spectrum of intrahepatic, perihilar, and distal tumors. Annals of surgery. 1996;224(4):463-

35973 ; discussion 73-5.

360 2. DeOliveira ML, Cunningham SC, Cameron JL, Kamangar F, Winter JM, Lillemoe KD, Choti MA, Yeo CJ, 361 Schulick RD. Cholangiocarcinoma: Thirty-one-year experience with 564 patients at a single institution. Annals of 362 Surgery. 2007;245(5):755-62.

363 3. Italian Clinical Practice Guidelines on Cholangiocarcinoma - Part I: Classification, diagnosis and staging.

364 Digestive and liver disease : official journal of the Italian Society of Gastroenterology and the Italian Association for 365 the Study of the Liver. 2020;52(11):1282-93.

366 4. Ebata T, Mizuno T, Yokoyama Y, Igami T, Sugawara G, Nagino M. Surgical resection for Bismuth type IV 367 perihilar cholangiocarcinoma. The British journal of surgery. 2018;105(7):829-38.

368 5. Popescu I, Dumitrascu T. Curative-intent surgery for hilar cholangiocarcinoma: prognostic factors for clinical 369 decision making. Langenbeck's archives of surgery. 2014;399(6):693-705.

370 6. Higuchi R, Yazawa T, Uemura S, Izumo W, Ota T, Kiyohara K, Furukawa T, Egawa H, Yamamoto M.

371 Surgical Outcomes for Perihilar Cholangiocarcinoma with Vascular Invasion. Journal of gastrointestinal surgery :

372 official journal of the Society for Surgery of the Alimentary Tract. 2019;23(7):1443-53.

373 7. Mizuno T, Ebata T, Yokoyama Y, Igami T, Yamaguchi J, Onoe S, Watanabe N, Kamei Y, Nagino M. 374 Combined Vascular Resection for Locally Advanced Perihilar Cholangiocarcinoma. Annals of surgery. 2020.

375 8. Schimizzi GV, Jin LX, Davidson JTt, Krasnick BA, Ethun CG, Pawlik TM, Poultsides G, Tran T, Idrees K, 376 Isom CA, Weber SM, Salem A, Hawkins WG, Strasberg SM, Doyle MB, Chapman WC, Martin RCG, Scoggins C, 377 Shen P, Mogal HD, Schmidt C, Beal E, Hatzaras I, Shenoy R, Maithel SK, Fields RC. Outcomes after vascular 378 resection during curative-intent resection for hilar cholangiocarcinoma: a multi-institution study from the US 379 extrahepatic biliary malignancy consortium. HPB (Oxford). 2018;20(4):332-9.

380 9. She WH, Cheung TT, Ma KW, Tsang SHY, Dai WC, Chan ACY, Lo CM. Vascular resection and 381 reconstruction in hilar cholangiocarcinoma. ANZ journal of surgery. 2020;90(9):1653-9.

382 10. Yu Z, Sun Q, Zhu Y, Wang J, Xu J. Combined vascular resection and reconstruction for advanced hilar 383 cholangiocarcinoma. International Journal of Clinical and Experimental Medicine. 2017;10(2):2695-705.

384 11. Ramos E. Principles of surgical resection in hilar cholangiocarcinoma. World journal of gastrointestinal 385 oncology. 2013;5(7):139-46.

386 12. Ebata T, Nagino M, Kamiya J, Uesaka K, Nagasaka T, Nimura Y. Hepatectomy with portal vein resection for 387 hilar cholangiocarcinoma: audit of 52 consecutive cases. Annals of surgery. 2003;238(5):720-7.

388 13. Miyazaki M, Kato A, Ito H, Kimura F, Shimizu H, Ohtsuka M, Yoshidome H, Yoshitomi H, Furukawa K, 389 Nozawa S. Combined vascular resection in operative resection for hilar cholangiocarcinoma: does it work or not? 390 Surgery. 2007;141(5):581-8.

391 14. Hemming A, Mekeel K, Khanna A, Baquerizo A, Kim R. Portal vein resection in management of hilar 392 cholangiocarcinoma. Journal of the American College of Surgeons. 2011;212(4):604-13; discussion 13-6.

393 15. Hoffmann K, Luible S, Goeppert B, Weiss K, Hinz U, Büchler M, Schemmer P. Impact of portal vein resection 394 on oncologic long-term outcome in patients with hilar cholangiocarcinoma. Surgery. 2015;158(5):1252-60.

395 16. Peng C, Li C, Wen T, Yan L, Li B. Left hepatectomy combined with hepatic artery resection for hilar 396 cholangiocarcinoma: A retrospective cohort study. International Journal of Surgery. 2016;32:167-73.

397 17. Shimada H, Endo I, Sugita M, Masunari H, Fujii Y, Tanaka K, Misuta K, Sekido H, Togo S. Hepatic resection 398 combined with portal vein or hepatic artery reconstruction for advanced carcinoma of the hilar bile duct and 
gallbladder. World journal of surgery. 2003;27(10):1137-42.

18. Yamanaka N, Yasui C, Yamanaka J, Ando T, Kuroda N, Maeda S, Ito T, Okamoto E. Left hemihepatectomy with microsurgical reconstruction of the right-sided hepatic vasculature. A strategy for preserving hepatic function in patients with proximal bile duct cancer. Langenbeck's archives of surgery. 2001;386(5):364-8.

19. Miyazaki M, Kato A, Ito H, Kimura F, Shimizu H, Ohtsuka M, Yoshidome H, Yoshitomi H, Furukawa K, Nozawa S. Combined vascular resection in operative resection for hilar cholangiocarcinoma: Does it work or not? Surgery. 2007;141(5):581-8.

20. Nagino M, Nimura Y, Nishio H, Ebata T, Igami T, Matsushita M, Nishikimi N, Kamei Y. Hepatectomy with simultaneous resection of the portal vein and hepatic artery for advanced perihilar cholangiocarcinoma: An audit of 50 consecutive cases. Annals of Surgery. 2010;252(1):115-23.

21. Abbas S, Sandroussi C. Systematic review and meta-analysis of the role of vascular resection in the treatment of hilar cholangiocarcinoma. HPB : the official journal of the International Hepato Pancreato Biliary Association. 2013;15(7):492-503.

22. Chen W, Ke K, Chen Y. Combined portal vein resection in the treatment of hilar cholangiocarcinoma: a systematic review and meta-analysis. European journal of surgical oncology : the journal of the European Society of Surgical Oncology and the British Association of Surgical Oncology. 2014;40(5):489-95.

23. Wu X, Dong P, Gu J, Li M, Wu W, Lu J, Mu J, Ding Q, Zhang L, Ding Q, Weng H, Liu Y. Combined portal vein resection for hilar cholangiocarcinoma: a meta-analysis of comparative studies. Journal of gastrointestinal surgery : official journal of the Society for Surgery of the Alimentary Tract. 2013;17(6):1107-15.

24. Yu W, Shao M, Gu Z, Shi S, Shen N, Zhang Y. Effect evaluation of vascular resection for patients with hilar cholangiocarcinoma: original data and meta-analysis. Hepato-gastroenterology. 2014;61(130):307-13.

25. Italian Clinical Practice Guidelines on Cholangiocarcinoma - Part II: Treatment. Digestive and liver disease : official journal of the Italian Society of Gastroenterology and the Italian Association for the Study of the Liver. 2020;52(12):1430-42.

26. Liberati A, Altman D, Tetzlaff J, Mulrow C, Gøtzsche P, Ioannidis J, Clarke M, Devereaux P, Kleijnen J, Moher D. The PRISMA statement for reporting systematic reviews and meta-analyses of studies that evaluate health care interventions: explanation and elaboration. Journal of clinical epidemiology. 2009;62(10):e1-34.

27. Tierney J, Stewart L, Ghersi D, Burdett S, Sydes M. Practical methods for incorporating summary time-toevent data into meta-analysis. Trials. 2007;8:16.

28. Stang A. Critical evaluation of the Newcastle-Ottawa scale for the assessment of the quality of nonrandomized studies in meta-analyses. European journal of epidemiology. 2010;25(9):603-5.

29. Dindo D, Demartines N, Clavien P. Classification of surgical complications: a new proposal with evaluation in a cohort of 6336 patients and results of a survey. Annals of surgery. 2004;240(2):205-13.

30. De Jong MC, Marques H, Clary BM, Bauer TW, Marsh JW, Ribero D, Majno P, Hatzaras I, Walters DM, Barbas AS, Mega R, Schulick RD, Choti MA, Geller DA, Barroso E, Mentha G, Capussotti L, Pawlik TM. The impact of portal vein resection on outcomes for hilar cholangiocarcinoma: A multi-institutional analysis of 305 cases. Cancer. 2012;118(19):4737-47.

31. Dumitraşcu T, Stroescu C, Braşoveanu V, Herlea V, Ionescu M, Popescu I. Curative-intent Surgery for Perihilar Cholangiocarcinoma with and without Portal Vein Resection - A Comparative Analysis of Early and Late Outcomes. Chirurgia (Bucharest, Romania : 1990). 2017;112(3):308-19.

32. Ebata T, Nagino M, Kamiya J, Uesaka K, Nagasaka T, Nimura Y. Hepatectomy with Portal Vein Resection for 
440 Hilar Cholangiocarcinoma: Audit of 52 Consecutive Cases. Annals of Surgery. 2003;238(5):720-7.

441 33. Hemming AW, Mekeel K, Khanna A, Baquerizo A, Kim RD. Portal vein resection in management of hilar

442 cholangiocarcinoma. Journal of the American College of Surgeons. 2011;212(4):604-13.

443 34. Hoffmann K, Luible S, Goeppert B, Weiss KH, Hinz U, Büchler MW, Schemmer P. Impact of portal vein

444 resection on oncologic long-term outcome in patients with hilar cholangiocarcinoma. Surgery (United States).

$445 \quad 2015 ; 158(5): 1252-60$.

446 35. Igami T, Nishio H, Ebata T, Yokoyama Y, Sugawara G, Nimura Y, Nagino M. Surgical treatment of hilar

447 cholangiocarcinoma in the "new era": The Nagoya University experience. Journal of Hepato-Biliary-Pancreatic

448 Sciences. 2010;17(4):449-54.

449 36. Klempnauer J, Ridder GJ, Von Wasielewski R, Werner M, Weimann A, Pichlmayr R. Resectional surgery of

450 hilar cholangiocarcinoma: A multivariate analysis of prognostic factors. Journal of Clinical Oncology.

451 1997;15(3):947-54.

452 37. Kondo S, Hirano S, Ambo Y, Tanaka E, Okushiba S, Morikawa T, Katoh H. Forty consecutive resections of

453 hilar cholangiocarcinoma with no postoperative mortality and no positive ductal margins: Results of a prospective

454 study. Annals of Surgery. 2004;240(1):95-101.

455 38. Lee SG, Song GW, Hwang S, Ha TY, Moon DB, Jung DH, Kim KH, Ahn CS, Kim MH, Lee SK, Sung KB,

456 Ko GY. Surgical treatment of hilar cholangiocarcinoma in the new era: The Asan experience. Journal of Hepato-

457 Biliary-Pancreatic Sciences. 2010;17(4):476-89.

458 39. Matsuyama R, Mori R, Ota Y, Homma Y, Kumamoto T, Takeda K, Morioka D, Maegawa J, Endo I.

459 Significance of Vascular Resection and Reconstruction in Surgery for Hilar Cholangiocarcinoma: With Special

460 Reference to Hepatic Arterial Resection and Reconstruction. Annals of Surgical Oncology. 2016;23:475-84.

461 40. Muñoz L, Roayaie S, Maman D, Fishbein T, Sheiner P, Emre S, Miller C, Schwartz ME. Hilar

462 cholangiocarcinoma involving the portal vein bifurcation: Long-term results after resection. Journal of Hepato-

463 Biliary-Pancreatic Surgery. 2002;9(2):237-41.

464 41. Song GW, Lee SG, Hwang S, Kim KH, Cho YP, Ahn CS, Moon DB, Ha TY. Does portal vein resection with

465 hepatectomy improve survival in locally advanced hilar cholangiocarcinoma? Hepato-Gastroenterology.

$4662009 ; 56(93): 935-42$.

467 42. Tamoto E, Hirano S, Tsuchikawa T, Tanaka E, Miyamoto M, Matsumoto J, Kato K, Shichinohe T. Portal vein 468 resection using the no-touch technique with a hepatectomy for hilar cholangiocarcinoma. HPB. 2014;16(1):56-61.

469 43. Wang ST, Shen SL, Peng BG, Hua YP, Chen B, Kuang M, Li SQ, He Q, Liang LJ. Combined vascular

470 resection and analysis of prognostic factors for hilar cholangiocarcinoma. Hepatobiliary and Pancreatic Diseases

471 International. 2015;14(6):626-32.

472 44. Cai W, Sima H, Chen B, Yang G. Risk factors for hilar cholangiocarcinoma: a case-control study in China.

473 World journal of gastroenterology. 2011;17(2):249-53.

474 45. Hayashi S, Miyazaki M, Kondo Y, Nakajima N. Invasive growth patterns of hepatic hilar ductal carcinoma. A

475 histologic analysis of 18 surgical cases. Cancer. 1994;73(12):2922-9.

476 46. Parikh A, Abdalla E, Vauthey J. Operative considerations in resection of hilar cholangiocarcinoma. HPB : the

477 official journal of the International Hepato Pancreato Biliary Association. 2005;7(4):254-8.

478 47. Ruys A, Busch O, Gouma D, van Gulik T. Staging laparoscopy for hilar cholangiocarcinoma: is it still

479 worthwhile? Annals of surgical oncology. 2011;18(9):2647-53.

480 48. Nagino M. Perihilar cholangiocarcinoma: a surgeon's viewpoint on current topics. Journal of gastroenterology.

Peer] reviewing PDF | (2021:04:60471:2:0:NEW 22 Aug 2021) 
2012;47(11):1165-76.

49. Nagino M, Ebata T, Yokoyama Y, Igami T, Sugawara G, Takahashi Y, Nimura Y. Evolution of surgical treatment for perihilar cholangiocarcinoma: a single-center 34-year review of 574 consecutive resections. Annals of surgery. 2013;258(1):129-40.

50. Mansour J, Aloia T, Crane C, Heimbach J, Nagino M, Vauthey J. Hilar cholangiocarcinoma: expert consensus statement. HPB : the official journal of the International Hepato Pancreato Biliary Association. 2015;17(8):691-9. 51. Neuhaus P, Jonas S, Bechstein W, Lohmann R, Radke C, Kling N, Wex C, Lobeck H, Hintze R. Extended resections for hilar cholangiocarcinoma. Annals of surgery. 1999;230(6):808-18; discussion 19.

52. Neuhaus P, Thelen A, Jonas S, Puhl G, Denecke T, Veltzke-Schlieker W, Seehofer D. Oncological superiority of hilar en bloc resection for the treatment of hilar cholangiocarcinoma. Annals of surgical oncology. 2012;19(5):1602-8.

53. Hirano S, Kondo S, Tanaka E, Shichinohe T, Tsuchikawa T, Kato K, Matsumoto J, Kawasaki R. Outcome of surgical treatment of hilar cholangiocarcinoma: a special reference to postoperative morbidity and mortality. Journal of hepato-biliary-pancreatic sciences. 2010;17(4):455-62.

54. Zhang C, Li T, Chen Z, Chen Q, Zhi X. Risk factors, management, and prognosis for liver abscess after radical resection of hilar cholangiocarcinoma. International journal of clinical and experimental medicine. 2015;8(11):21279-86.

55. Kinoshita H, Sakai K, Hirohashi K, Igawa S, Yamasaki O, Kubo S. Preoperative portal vein embolization for hepatocellular carcinoma. World journal of surgery. 1986;10(5):803-8.

56. Makuuchi M, Thai B, Takayasu K, Takayama T, Kosuge T, Gunvén P, Yamazaki S, Hasegawa H, Ozaki H. Preoperative portal embolization to increase safety of major hepatectomy for hilar bile duct carcinoma: a preliminary report. Surgery. 1990;107(5):521-7.

57. Baton O, Azoulay D, Adam D, Castaing D. Major hepatectomy for hilar cholangiocarcinoma type 3 and 4: prognostic factors and longterm outcomes. Journal of the American College of Surgeons. 2007;204(2):250-60. 58. Hidalgo E, Asthana S, Nishio H, Wyatt J, Toogood G, Prasad K, Lodge J. Surgery for hilar cholangiocarcinoma: the Leeds experience. European journal of surgical oncology : the journal of the European Society of Surgical Oncology and the British Association of Surgical Oncology. 2008;34(7):787-94.

59. Lee J, Hwang D, Lee S, Park K, Lee Y. The proximal margin of resected hilar cholangiocarcinoma: the effect of microscopic positive margin on long-term survival. The American surgeon. 2012;78(4):471-7.

60. Lurje G, Bednarsch J, Czigany Z, Lurje I, Schlebusch I, Boecker J, Meister F, Tacke F, Roderburg C, Den Dulk M, Gaisa N, Bruners P, Neumann U. The prognostic role of lymphovascular invasion and lymph node metastasis in perihilar and intrahepatic cholangiocarcinoma. European journal of surgical oncology : the journal of the European Society of Surgical Oncology and the British Association of Surgical Oncology. 2019;45(8):1468-78. 61. Miyazaki M, Yoshitomi H, Miyakawa S, Uesaka K, Unno M, Endo I, Ota T, Ohtsuka M, Kinoshita H, Shimada K, Shimizu H, Tabata M, Chijiiwa K, Nagino M, Hirano S, Wakai T, Wada K, Isayama H, Iasayama H, Okusaka T, Tsuyuguchi T, Fujita N, Furuse J, Yamao K, Murakami K, Yamazaki H, Kijima H, Nakanuma Y, Yoshida M, Takayashiki T, Takada T. Clinical practice guidelines for the management of biliary tract cancers 2015: the 2nd English edition. Journal of hepato-biliary-pancreatic sciences. 2015;22(4):249-73.

62. Rizvi S, Khan S, Hallemeier C, Kelley R, Gores G. Cholangiocarcinoma - evolving concepts and therapeutic strategies. Nature reviews Clinical oncology. 2018;15(2):95-111.

63. Banales J, Marin J, Lamarca A, Rodrigues P, Khan S, Roberts L, Cardinale V, Carpino G, Andersen J, Braconi 
522 C, Calvisi D, Perugorria M, Fabris L, Boulter L, Macias R, Gaudio E, Alvaro D, Gradilone S, Strazzabosco M, 523 Marzioni M, Coulouarn C, Fouassier L, Raggi C, Invernizzi P, Mertens J, Moncsek A, Rizvi S, Heimbach J, 524 Koerkamp B, Bruix J, Forner A, Bridgewater J, Valle J, Gores G. Cholangiocarcinoma 2020: the next horizon in 525 mechanisms and management. Nature reviews Gastroenterology \& hepatology. 2020;17(9):557-88.

526 64. Groot Koerkamp B, Wiggers J, Allen P, Busch O, D'Angelica M, DeMatteo R, Fong Y, Gonen M, Gouma D, 527 Kingham T, van Gulik T, Jarnagin W. American Joint Committee on Cancer staging for resected perihilar

528 cholangiocarcinoma: a comparison of the 6th and 7th editions. HPB : the official journal of the International Hepato 529 Pancreato Biliary Association. 2014;16(12):1074-82. 


\section{Table $\mathbf{1}$ (on next page)}

Studies included in the current meta-analysis 
1 Table 1 Studies included in the current meta-analysis

\begin{tabular}{|c|c|c|c|c|c|c|c|c|c|c|}
\hline Study (Year) & Country & Period & $\begin{array}{c}\text { No of } \\
\text { Patients }\end{array}$ & Male, \% & $\begin{array}{l}\text { Age (median } \\
\text { or mean) }\end{array}$ & $\begin{array}{l}\text { Blood loss } \\
(\mathrm{ml})\end{array}$ & $\begin{array}{c}\text { 90-day } \\
\text { mortality, }\end{array}$ & $\begin{array}{c}\text { Overall } \\
\text { morbidity, }\end{array}$ & R0, \% & $\begin{array}{c}\text { Hepatic } \\
\text { insufficiency }\end{array}$ \\
\hline \multirow[t]{3}{*}{ Wang et al. (2015) } & China & 2005-2012 & PVR:16 & $4(25 \%)$ & 53 & $980 \pm 511$ & $0(0 \%)$ & $6(38 \%)$ & NR & $0(0 \%)$ \\
\hline & & & HAR:24 & $18(75 \%)$ & 60 & $1175 \pm 713$ & $1(4 \%)$ & $10(42 \%)$ & NR & $1(6 \%)$ \\
\hline & & & No VR:114 & $70(61 \%)$ & 57 & $527 \pm 596$ & $4(4 \%)$ & $40(35 \%)$ & NR & $2(2 \%)$ \\
\hline \multirow[t]{2}{*}{ Dumitracu et al. (2017) } & Romania & 1996-2014 & PVR:21 & $17(81 \%)$ & 56 & $3475 \pm 2925$ & $2(10 \%)$ & NR & $15(71 \%)$ & $4(19 \%)$ \\
\hline & & & No VR:102 & $53(52 \%)$ & 59 & $400 \pm 2483$ & $5(5 \%)$ & NR & $80(78 \%)$ & $27(26 \%)$ \\
\hline \multirow[t]{2}{*}{ Ebata et al. (2003) } & Japan & $1979-2000$ & PVR:52 & $35(67 \%)$ & 60.3 & NR & NR & $44(85 \%)$ & $36(69 \%)$ & $14(27 \%)$ \\
\hline & & & No VR:108 & $81(75 \%)$ & 60.2 & NR & NR & $85(79 \%)$ & $95(88 \%)$ & $21(19 \%)$ \\
\hline \multirow[t]{3}{*}{ Nagino et al. (2010) } & Japan & 1997-2009 & PVR:92 & NR & 60 & NR & NR & NR & NR & NR \\
\hline & & & HAR:62 & NR & 60 & NR & NR & NR & NR & NR \\
\hline & & & No VR:211 & NR & NR & NR & NR & NR & NR & NR \\
\hline \multirow[t]{2}{*}{ Hoffmann et al. (2015) } & Germany & 2001-2012 & PVR:21 & $9(43 \%)$ & 65 & NR & $4(19 \%)$ & NR & $12(57 \%)$ & $12(57 \%)$ \\
\hline & & & No VR:39 & $28(72 \%)$ & 68 & NR & $5(13 \%)$ & NR & $23(59 \%)$ & $17(44 \%)$ \\
\hline \multirow[t]{2}{*}{ Peng et al. (2016) } & China & 2005-2012 & HAR:26 & $18(69 \%)$ & 59 & $327 \pm 146$ & NR & $15(58 \%)$ & $22(85 \%)$ & $5(19 \%)$ \\
\hline & & & No VR:35 & $20(57 \%)$ & 63 & $400 \pm 209$ & NR & $15(43 \%)$ & $28(80 \%)$ & $3(9 \%)$ \\
\hline \multirow[t]{3}{*}{ Schimizzi et al (2017). } & United States & 1998-2015 & PVR:19 & $10(53 \%)$ & 62 & NR & NR & $13(68 \%)$ & $14(74 \%)$ & $3(16 \%)$ \\
\hline & & & HAR:12 & $6(50 \%)$ & 52 & NR & NR & $6(50 \%)$ & $8(67 \%)$ & $0(0 \%)$ \\
\hline & & & No VR:170 & $69(41 \%)$ & 66 & NR & NR & $114(67 \%)$ & $119(70 \%)$ & $7(4 \%)$ \\
\hline \multirow[t]{2}{*}{ Hemming et al. (2011) } & United States & 1999-2010 & PVR:42 & NR & NR & NR & NR & NR & NR & NR \\
\hline & & & No VR:53 & NR & NR & NR & NR & NR & NR & NR \\
\hline
\end{tabular}




\begin{tabular}{|c|c|c|c|c|c|c|c|c|c|c|}
\hline Study (Year) & Country & Period & $\begin{array}{c}\text { No of } \\
\text { Patients }\end{array}$ & Male, \% & $\begin{array}{l}\text { Age (median } \\
\text { or mean) }\end{array}$ & $\begin{array}{l}\text { Blood loss } \\
(\mathrm{ml})\end{array}$ & $\begin{array}{c}\text { 90-day } \\
\text { mortality, }\end{array}$ & $\begin{array}{c}\text { Overall } \\
\text { morbidity, }\end{array}$ & R0, \% & $\begin{array}{c}\text { Hepatic } \\
\text { insufficiency, }\end{array}$ \\
\hline \multirow[t]{2}{*}{ Tamoto et al. (2014) } & Japan & 2005-2009 & PVR:36 & $25(69 \%)$ & 68.5 & $1902 \pm 1287$ & $0(0 \%)$ & $21(58 \%)$ & $28(78 \%)$ & $2(6 \%)$ \\
\hline & & & No VR:13 & $10(77 \%)$ & 68 & $1980 \pm 867$ & $2(15 \%)$ & $10(77 \%)$ & $12(92 \%)$ & $2(15 \%)$ \\
\hline \multirow[t]{3}{*}{ Higuchi et al. (2018) } & Japan & $2000-2016$ & PVR:56 & $38(68 \%)$ & 69.5 & NR & $3(5 \%)$ & NR & $35(63 \%)$ & NR \\
\hline & & & HAR:19 & $13(68 \%)$ & 67.0 & NR & $3(16 \%)$ & NR & $12(63 \%)$ & NR \\
\hline & & & No VR:174 & $126(72 \%)$ & 70.0 & NR & $3(2 \%)$ & NR & $115(66 \%)$ & NR \\
\hline \multirow[t]{3}{*}{ Lee et al. (2009) } & Korea & 2001-2008 & PVR:38 & NR & NR & $\mathrm{NR}$ & $\mathrm{NR}$ & $\mathrm{NR}$ & NR & NR \\
\hline & & & HAR:5 & $\mathrm{NR}$ & $\mathrm{NR}$ & NR & NR & $\mathrm{NR}$ & NR & NR \\
\hline & & & No VR:259 & NR & $\mathrm{NR}$ & NR & NR & NR & NR & NR \\
\hline \multirow[t]{3}{*}{ Igami et al (2009) } & Japan & 2001-2008 & PVR:69 & NR & NR & NR & NR & NR & NR & NR \\
\hline & & & HAR:53 & NR & NR & NR & NR & NR & NR & NR \\
\hline & & & No VR:176 & NR & $\mathrm{NR}$ & NR & $\mathrm{NR}$ & NR & NR & NR \\
\hline \multirow[t]{3}{*}{ She et al. (2020) } & China & 1989-2016 & PVR:17 & $14(64 \%)$ & 57.0 & $2875 \pm 1875$ & $1(5 \%)$ & $11(50 \%)$ & $10(45 \%)$ & NR \\
\hline & & & HAR:5 & & & & & & & \\
\hline & & & No VR:68 & $49(72 \%)$ & 67.5 & $1465 \pm 4925$ & $11(16 \%)$ & $41(60 \%)$ & $38(56 \%)$ & NR \\
\hline \multirow[t]{3}{*}{ Kondo et al. (2004) } & Japan & 1999-2002 & PVR:6 & NR & NR & NR & NR & NR & NR & NR \\
\hline & & & HAR:8 & NR & NR & NR & NR & NR & NR & NR \\
\hline & & & No VR:26 & NR & NR & NR & NR & NR & NR & NR \\
\hline \multirow[t]{2}{*}{ Jong et al. (2012) } & United States & 1984-2010 & PVR:51 & $29(57 \%)$ & 66 & NR & $9(18 \%)$ & NR & $34(67 \%)$ & NR \\
\hline & & & No VR:173 & $100(58 \%)$ & 66 & NR & $26(15 \%)$ & NR & $115(66 \%)$ & NR \\
\hline \multirow[t]{3}{*}{ Miyazaki et al. (2007) } & Japan & 1981-2004 & PVR:34 & $18(53 \%)$ & 64 & $1975 \pm 1474$ & $3(9 \%)$ & $13(38 \%)$ & NR & NR \\
\hline & & & HAR:9 & $7(78 \%)$ & 59 & $1726 \pm 1253$ & $3(33 \%)$ & $7(78 \%)$ & NR & NR \\
\hline & & & No VR:118 & $77(65 \%)$ & 65 & $1523 \pm 1147$ & $5(4 \%)$ & $42(36 \%)$ & NR & NR \\
\hline
\end{tabular}




\begin{tabular}{|c|c|c|c|c|c|c|c|c|c|c|}
\hline Study (Year) & Country & Period & $\begin{array}{c}\text { No of } \\
\text { Patients }\end{array}$ & Male, \% & $\begin{array}{l}\text { Age (median } \\
\text { or mean) }\end{array}$ & $\begin{array}{l}\text { Blood loss } \\
(\mathrm{ml})\end{array}$ & $\begin{array}{l}\text { 90-day } \\
\text { mortality, }\end{array}$ & $\begin{array}{c}\text { Overall } \\
\text { morbidity, }\end{array}$ & R0, \% & $\begin{array}{c}\text { Hepatic } \\
\text { insufficiency, }\end{array}$ \\
\hline \multirow[t]{2}{*}{ Muñoz et al. (2002) } & United States & 1990-2001 & PVR:10 & $7(70 \%)$ & 61 & NR & NR & NR & NR & NR \\
\hline & & & No VR:18 & $5(28 \%)$ & 66 & NR & NR & NR & NR & NR \\
\hline \multirow[t]{3}{*}{ Klempnauer et al. (1997) } & Germany & 1971-1995 & PVR:40 & $\mathrm{NR}$ & NR & NR & NR & NR & $30(73 \%)$ & NR \\
\hline & & & HAR:1 & NR & NR & NR & NR & NR & NR & NR \\
\hline & & & No VR:77 & NR & NR & NR & NR & NR & $55(71 \%)$ & NR \\
\hline \multirow[t]{3}{*}{ Matsuyama et al. (2016) } & Japan & 1992-2014 & PVR:54 & $39(72 \%)$ & 70 & $1981 \pm 1926$ & $2(4 \%)$ & $38(70 \%)$ & $43(80 \%)$ & $4(7 \%)$ \\
\hline & & & HAR:44 & $27(61 \%)$ & 69 & $2212 \pm 2192$ & $4(9 \%)$ & $36(82 \%)$ & $35(80 \%)$ & $5(11 \%)$ \\
\hline & & & No VR:74 & $55(74 \%)$ & 69 & $1929 \pm 1387$ & $3(4 \%)$ & $61(82 \%)$ & $55(74 \%)$ & $6(8 \%)$ \\
\hline \multirow[t]{3}{*}{ Yu et al. (2017) } & China & 2006-2014 & PVR:10 & $\mathrm{NR}$ & 55.40 & NR & NR & $16(84 \%)$ & $\mathrm{NR}$ & $0(0 \%)$ \\
\hline & & & HAR:9 & $\mathrm{NR}$ & & & & & & \\
\hline & & & No VR:76 & $43(57 \%)$ & 61.03 & NR & $\mathrm{NR}$ & $45(59 \%)$ & $\mathrm{NR}$ & $4(5 \%)$ \\
\hline \multirow[t]{3}{*}{ Mizuno et al. (2020) } & Japan & 2001-2018 & PVR:157 & $49(31 \%)$ & 67 & $1498 \pm 1805$ & $3(2 \%)$ & $145(48 \%)$ & $108(69 \%)$ & $54(34 \%)$ \\
\hline & & & HAR:146 & $\mathrm{NR}$ & 67 & $1491 \pm 1146$ & $2(1 \%)$ & NR & $93(64 \%)$ & $49(34 \%)$ \\
\hline & & & No VR:484 & $162(33 \%)$ & 69 & $1078 \pm 891$ & $1(0 \%)$ & $242(50 \%)$ & $410(85 \%)$ & $102(21 \%)$ \\
\hline \multirow[t]{2}{*}{ Song et al. (2009) } & Korea & 1989-2005 & PVR:51 & $\mathrm{NR}$ & NR & NR & $5(10 \%)$ & $24(47 \%)$ & $\mathrm{NR}$ & $\mathrm{NR}$ \\
\hline & & & No VR:208 & NR & NR & NR & $6(3 \%)$ & $82(39 \%)$ & NR & NR \\
\hline
\end{tabular}

2 Abbreviations: VR, vascular resection; PVR, portal vein resection; HAR, hepatic artery resection; NR, not retrievable; UICC, Union for International

3 Cancer Control Unites. 


\section{Table 2 (on next page)}

Meta-analysis results of pooled survival in all included studies 
1 Table 2 Meta-analysis results of pooled survival in all included studies

\begin{tabular}{cccccc}
\hline & Group & I2 & Pooled OR & $95 \%$ CI & P value \\
\hline 1-year OS & VR & $55 \%$ & 0.94 & $0.54-1.64$ & 0.83 \\
& PVR & $48 \%$ & 0.77 & $0.49-1.20$ & 0.25 \\
3-year OS & HAR & $78 \%$ & 0.64 & $0.11-3.69$ & 0.62 \\
& VR & $35 \%$ & 0.56 & $0.46-0.68$ & $<0.00001$ \\
& PVR & $21 \%$ & 0.45 & $0.36-0.57$ & $<0.00001$ \\
5-year OS & HAR & $42 \%$ & 0.55 & $0.41-0.74$ & $<0.0001$ \\
& VR & $27 \%$ & 0.48 & $0.40-0.58$ & $<0.00001$ \\
& PVR & $54 \%$ & 0.52 & $0.35-0.76$ & 0.0008 \\
1-year DFS & HAR & $0 \%$ & 0.43 & $0.32-0.57$ & $<0.00001$ \\
3-year DFS & VR & $3 \%$ & 1.54 & $0.92-2.57$ & 0.10 \\
5-year DFS & VR & $0 \%$ & 1.00 & $059-1.71$ & 0.99 \\
\hline
\end{tabular}

2 Abbreviations: OR, Odds Ratio; CI, confidence interval; VR, vascular resection; PVR, portal vein resection;

3 HAR, hepatic artery resection; OS, overall survival; DFS, disease free survival.

4 
Figure 1

Flow chart showing the study selection process.

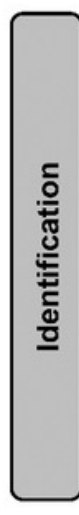

Records through database searching

1) PubMed $(n=583)$

2) Embase (n=1091)

3) Cochrane library $(n=18)$

4) Additional records identified through other sources $(n=1)$
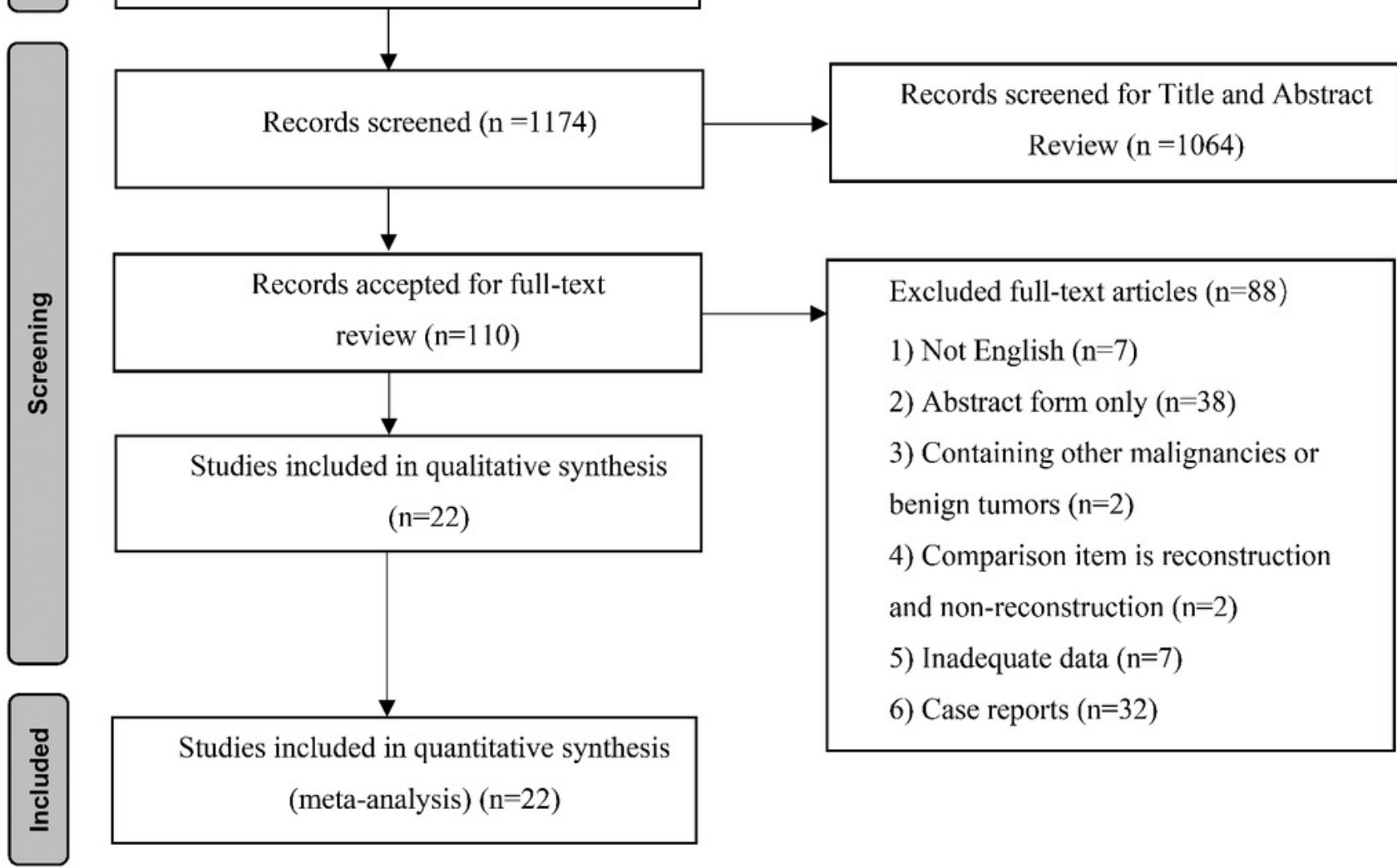
(meta-analysis) $(\mathrm{n}=22)$ 
Figure 2

Meta-analysis of studies on 90-day mortality.

(A) 90-day mortality rate in patients with and without VR; (B) 90-day mortality rate in patients with and without PVR; (C) 90-day mortality rate in patients with and without HAR. 
A

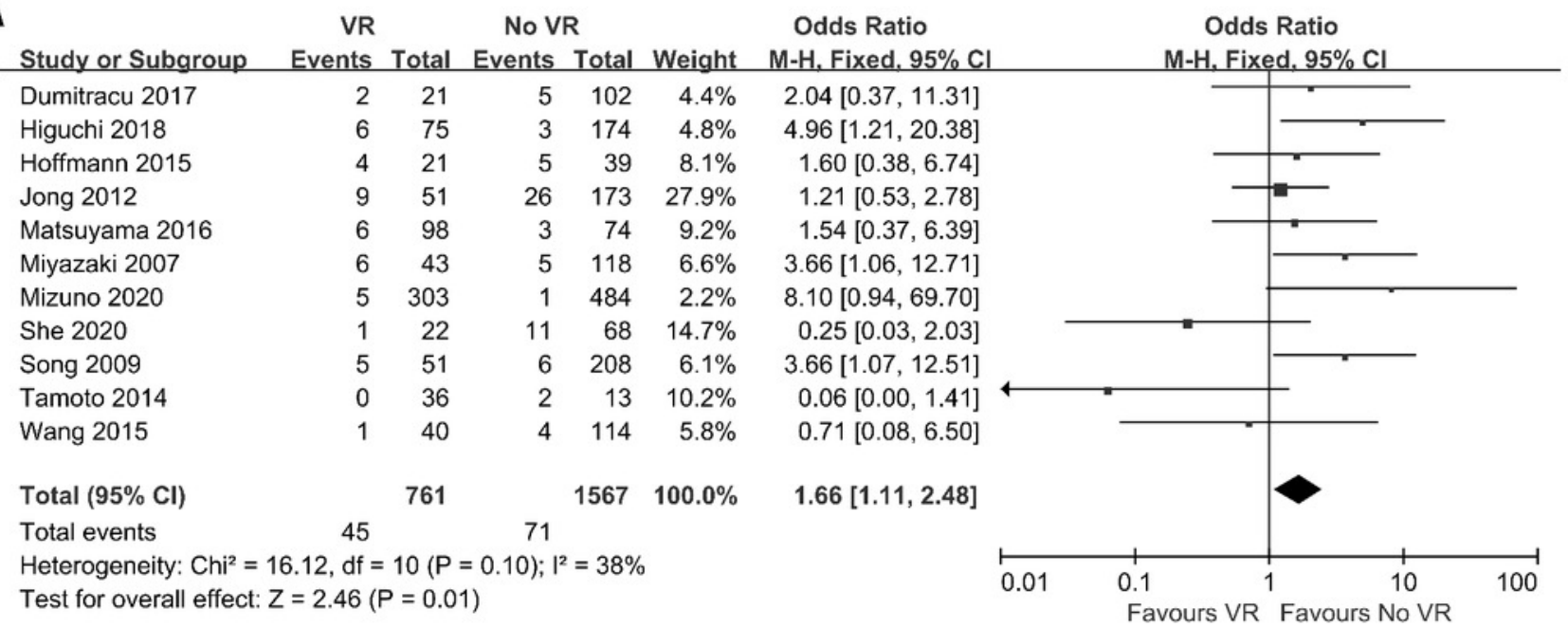

B

PVR No PVR

Odds Ratio

Odds Ratio

Study or Subgroup Events Total Events Total Weight M-H. Fixed. 95\% Cl Dumitracu 2017 Higuchi 2018

Hoffmann 2015

Jong 2012

Matsuyama 2016

Miyazaki 2007

Mizuno 2020

Song 2009

Tamoto 2014

Wang 2015

Total $(95 \% \mathrm{Cl})$

Total events

$\begin{array}{rrrrr}2 & 21 & 5 & 102 & 5.7 \% \\ 3 & 56 & 3 & 174 & 5.1 \% \\ 4 & 21 & 5 & 39 & 10.4 \% \\ 9 & 51 & 26 & 173 & 35.7 \% \\ 2 & 54 & 3 & 74 & 8.9 \% \\ 3 & 34 & 5 & 118 & 7.5 \% \\ 3 & 157 & 1 & 484 & 1.8 \% \\ 5 & 51 & 6 & 208 & 7.8 \% \\ 0 & 36 & 2 & 13 & 13.1 \% \\ 0 & 16 & 4 & 114 & 4.1 \%\end{array}$

$2.04[0.37,11.31]$

$3.23[0.63,16.46]$

$1.60[0.38,6.74]$

$1.21[0.53,2.78]$

$0.91[0.15,5.64]$

$2.19[0.50,9.66]$

$9.41[0.97,91.11]$

$3.66[1.07,12.51]$

$0.06[0.00,1.41]$

$0.74[0.04,14.46]$

497

$1499 \quad 100.0 \%$

$1.61[1.02,2.54]$ 60

Heterogeneity: $\mathrm{Chi}^{2}=10.23, \mathrm{df}=9(\mathrm{P}=0.33) ; \mathrm{I}^{2}=12 \%$

Test for overall effect: $Z=2.05(P=0.04)$

C

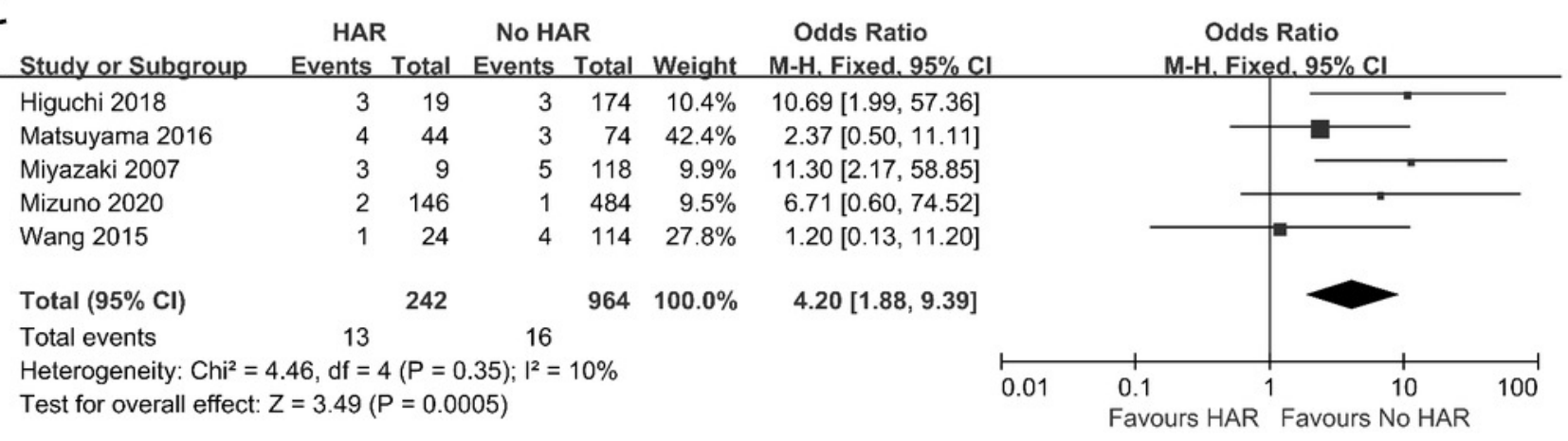


Figure 3

Meta-analysis of studies on overall morbidity.

(A) overall morbidity rate in patients with and without VR; (B) overall morbidity rate in patients with and without PVR; (C) overall morbidity rate in patients with and without HAR. 
A

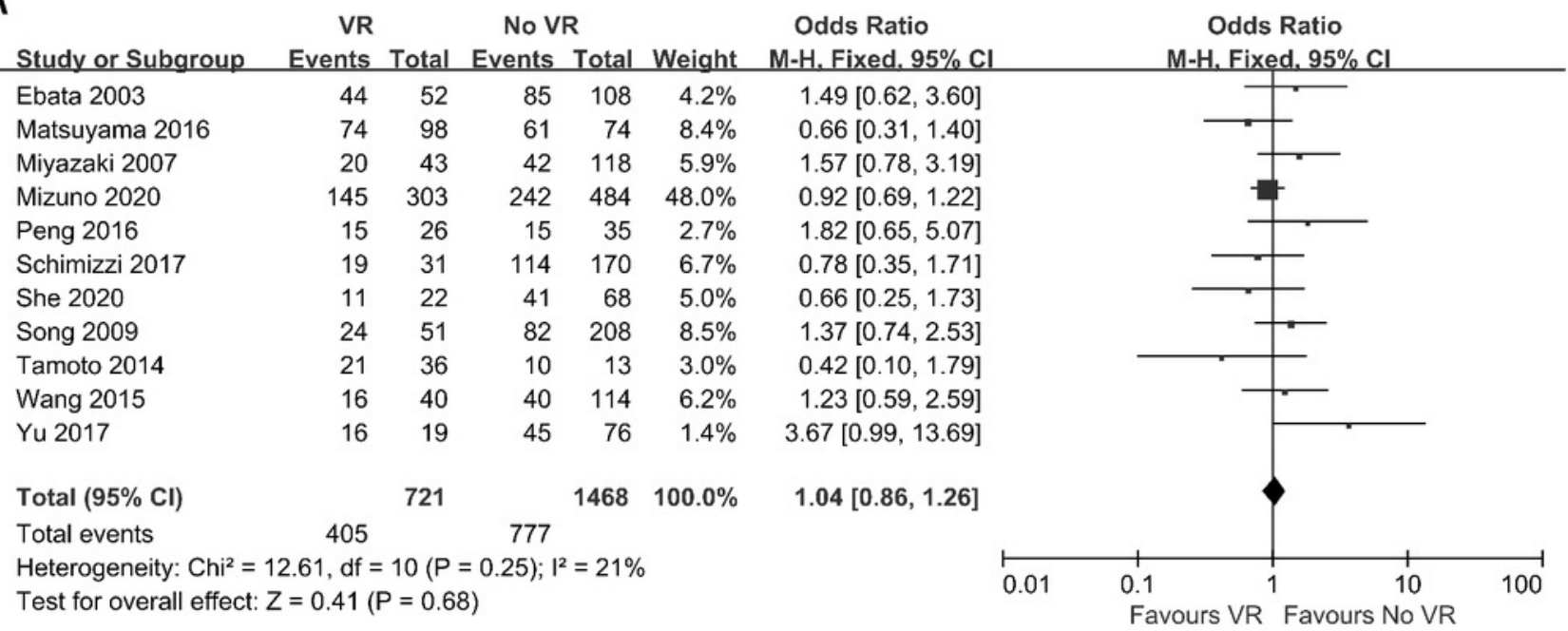

B

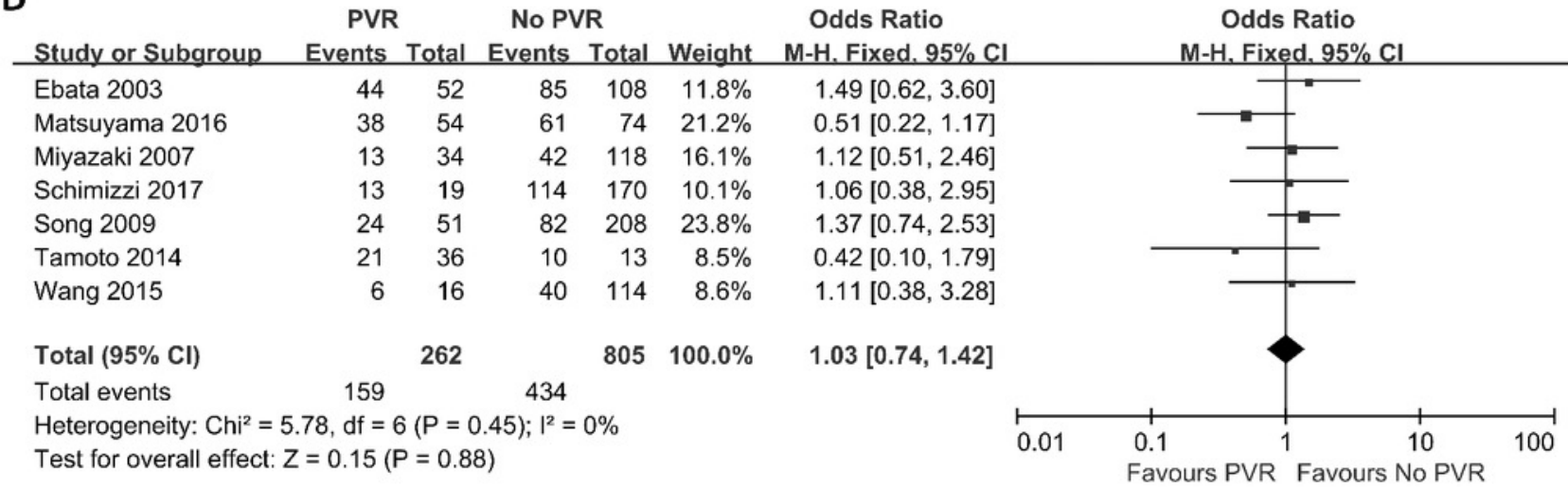

C

HAR No HAR Odds Ratio

Odds Ratio

Study or Subgroup Events Total Events Total Weight M-H. Fixed. 95\% Cl

$\begin{array}{lllllll}\text { Matsuyama } 2016 & 36 & 44 & 61 & 74 & 27.0 \% & 0.96[0.36,2.54]\end{array}$

$\begin{array}{lllllll}\text { Miyazaki } 2007 & 7 & 9 & 42 & 118 & 4.3 \% & 6.33[1.26,31.88]\end{array}$

Peng 2016

Schimizzi 2017

$\begin{array}{lllll}15 & 26 & 15 & 35 & 17.7 \%\end{array}$

$1.82[0.65,5.07]$

Wang 2015

Total $(95 \% \mathrm{Cl})$

$\begin{array}{rr}6 & 12 \\ 10 & 24\end{array}$

$114 \quad 170 \quad 24.5 \%$

$0.49[0.15,1.59]$

$1.32[0.54,3.24]$

Total events

$74 \quad 115 \quad 272$

Heterogeneity: $\mathrm{Chi}^{2}=7.12, \mathrm{df}=4(\mathrm{P}=0.13) ; \mathrm{I}^{2}=44 \%$

Test for overall effect: $Z=1.18(P=0.24)$

$1.32[0.83,2.11]$

$511 \quad 100.0 \%$

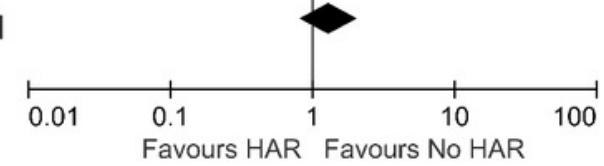


Figure 4

Meta-analysis of studies on posthepatectomy liver insufficiency (PHI).

(A) PHI rate in patients with and without VR; (B) PHI rate in patients with and without PVR; (C) $\mathrm{PHI}$ rate in patients with and without HAR. 


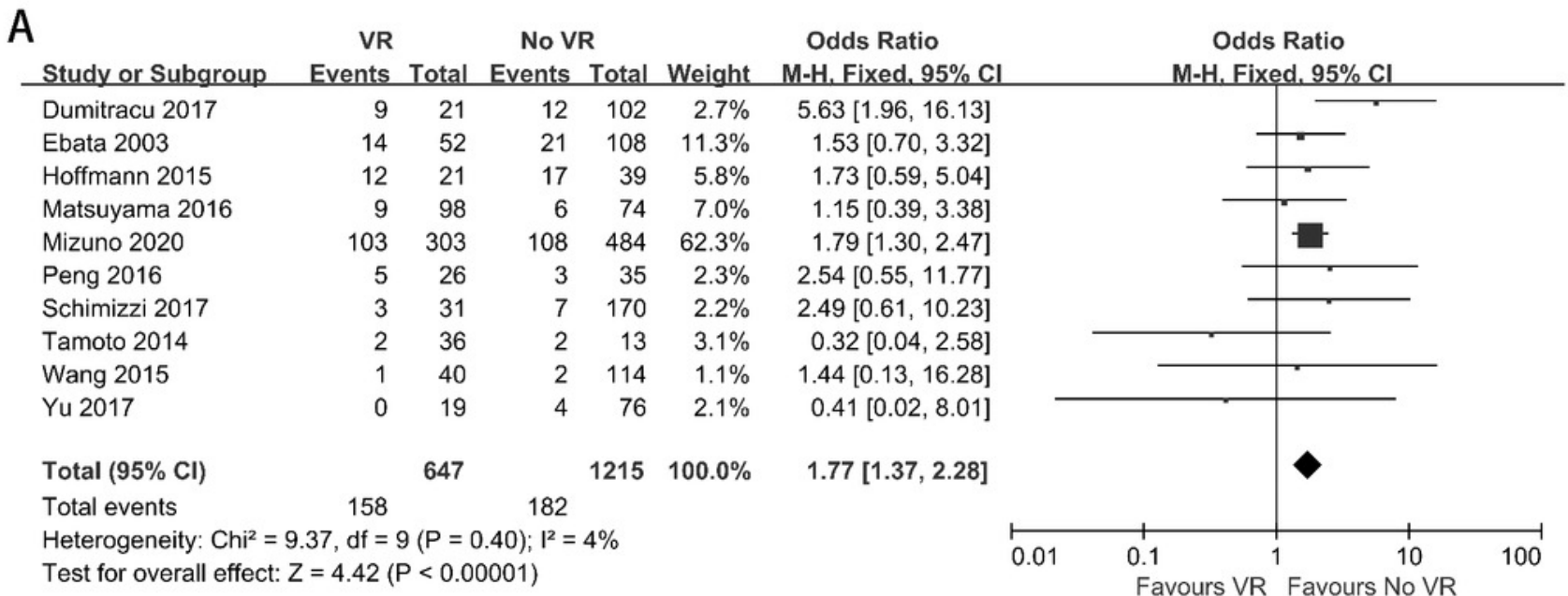

B

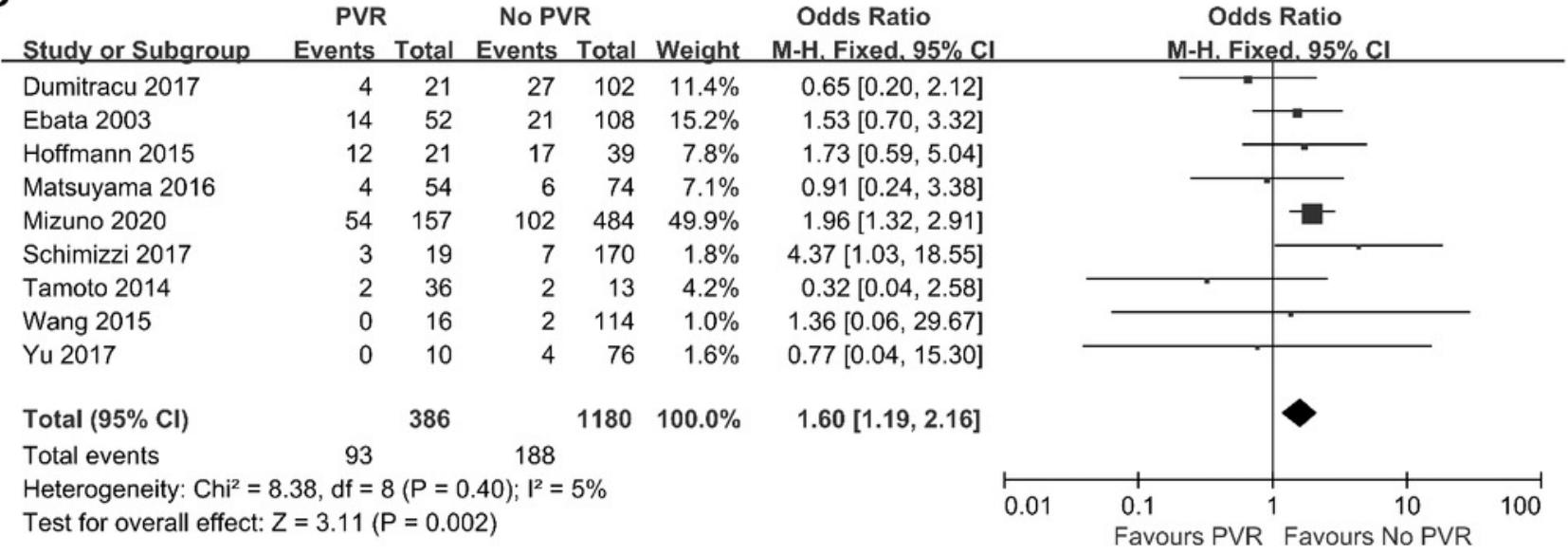

C

HAR No HAR Odds Ratio

Study or Subgroup Events Total Events Total Weight M-H. Fixed, 95\% Cl $\begin{array}{lllllll}\text { Matsuyama } 2016 & 5 & 44 & 6 & 74 & 9.7 \% & 1.45[0.42,5.07]\end{array}$

Mizuno 2020

Peng 2016

Schimizzi 2017

Wang 2015

$49 \quad 146$

$108 \quad 484 \quad 81.5 \%$

$1.76[1.17,2.64]$

$2.54[0.55,11.77]$

$0.87[0.05,16.17]$

$3.29[0.28,38.33]$

Total $(95 \% \mathrm{Cl})$

246

$\begin{array}{lll}7 & 170 & 2.5 \% \\ 2 & 114 & 1.3 \%\end{array}$

Total events

60

$877 \quad 100.0 \%$

Heterogeneity: $\mathrm{Chi}^{2}=0.78, \mathrm{df}=4(\mathrm{P}=0.94) ; \mathrm{I}^{2}=0 \%$

Test for overall effect: $Z=3.05(P=0.002)$

$1.77[1.23,2.54]$

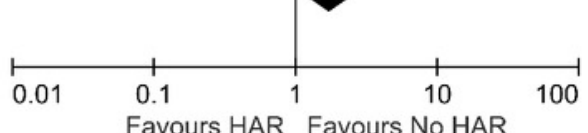


Figure 5

Meta-analysis of studies on R0 margin status.

(A) $R 0$ resection rate in patients with and without VR; (B) R0 resection rate in patients with and without PVR; (C) R0 resection rate in patients with and without HAR. 
A

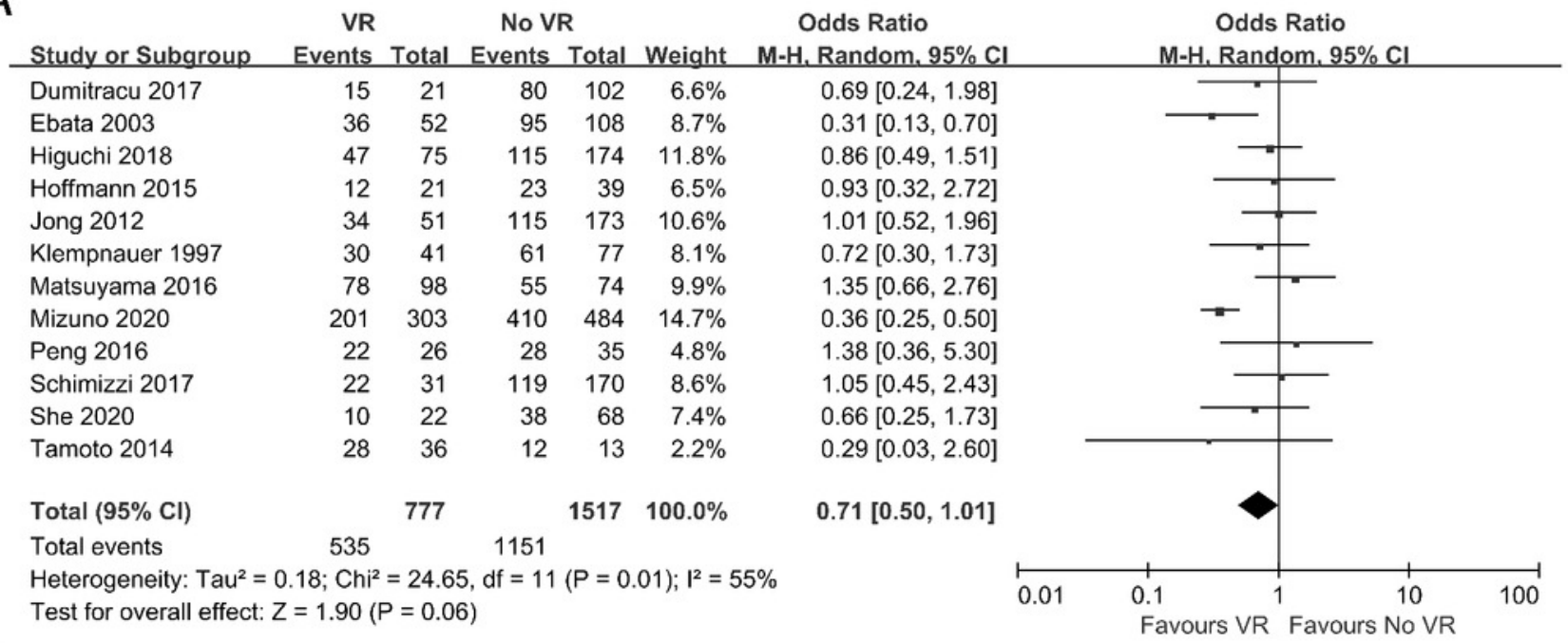

B

\begin{tabular}{cccc} 
& PVR & No PVR & Odds Ratio \\
Study or Subgroup & Events Total & Events Total Weight & M-H. Random, $95 \% \mathrm{Cl}$ \\
\hline
\end{tabular}

$\begin{array}{lllllll}\text { Dumitracu } 2017 & 15 & 21 & 80 & 102 & 8.7 \% & 0.69[0.24,1.98]\end{array}$

Ebata 2003

Higuchi 2018

Hoffmann 2015

Jong 2012

Matsuyama 2016

Mizuno 2020

Schimizzi 2017

Tamoto 2014

$36 \quad 52$

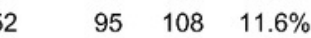

$\begin{array}{lllll}35 & 56 & 115 & 174 & 15.0 \%\end{array}$

$\begin{array}{lllll}12 & 21 & 23 & 39 & 8.5 \%\end{array}$

$\begin{array}{lllll}34 & 51 & 115 & 173 & 14.3 \%\end{array}$

$\begin{array}{lllll}43 & 54 & 55 & 74 & 11.4 \%\end{array}$

$\begin{array}{rrrrr}43 & 54 & 55 & 74 & 11.4 \% \\ 108 & 157 & 410 & 484 & 19.2 \%\end{array}$

Total $(95 \% \mathrm{Cl})$

$\begin{array}{rrrrr}14 & 19 & 119 & 170 & 8.5 \% \\ 28 & 36 & 12 & 13 & 2.8 \%\end{array}$

Total events

467

Heterogeneity: $\mathrm{Tau}^{2}=0.16 ; \mathrm{Chi}^{2}=15.92, \mathrm{df}=8(\mathrm{P}=0.04) ; \mathrm{I}^{2}=50 \%$

Test for overall effect: $Z=1.82(P=0.07)$

$0.31[0.13,0.70]$

$0.86[0.46,1.60]$

$0.93[0.32,2.72]$

$1.01[0.52,1.96]$

$1.35[0.58,3.14]$

$0.40[0.26,0.60]$

$1.20[0.41,3.51]$

$0.29[0.03,2.60]$

$0.70[0.47,1.03]$

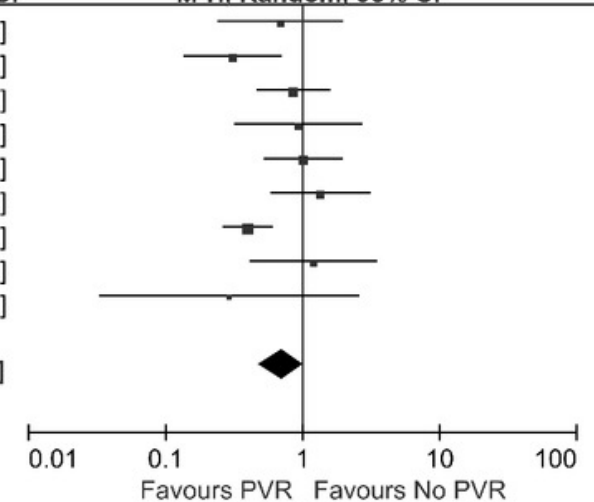

C

HAR No HAR

Odds Ratio

Odds Ratio

Study or Subgroup Events Total Events Total Weight M-H. Random. 95\% Cl

$\begin{array}{lrrrrr}\text { Higuchi 2018 } & 12 & 19 & 115 & 174 & 19.8 \% \\ \text { Matsuyama 2016 } & 35 & 44 & 55 & 74 & 21.0 \% \\ \text { Mizuno 2020 } & 93 & 146 & 410 & 484 & 27.8 \% \\ \text { Peng 2016 } & 22 & 26 & 28 & 35 & 15.1 \% \\ \text { Schimizzi 2017 } & 8 & 12 & 119 & 170 & 16.3 \% \\ & & & & & \\ \text { Total (95\% CI) } & & 247 & & 937 & 100.0 \% \\ \text { Total events } & 170 & & 727 & & \end{array}$

Heterogeneity: $\mathrm{Tau}^{2}=0.47 ; \mathrm{Chi}^{2}=13.43, \mathrm{df}=4(\mathrm{P}=0.009) ; \mathrm{I}^{2}=70 \%$

$0.88[0.33,2.35]$

$1.34[0.55,3.30]$

$0.32[0.21,0.48]$

$1.38[0.36,5.30]$

$0.86[0.25,2.97]$

$0.77[0.37,1.61]$

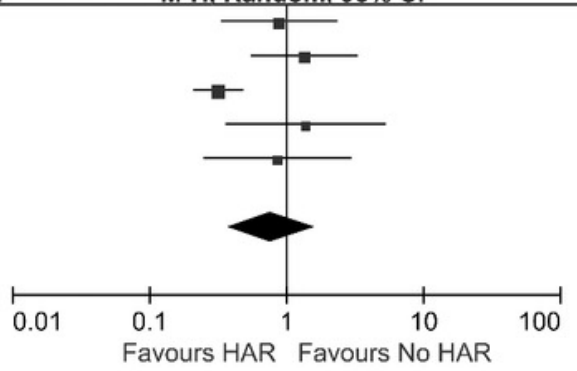


Figure 6

Funnel plots of main results in patients with and without VR.

(A) overall survival; (B) intraoperative blood loss; (C) proportion of III,IV stage according to UICC staging systems; (D) vascular invasion confirmed by histology. 
A

Study

Nagino ,2010

Schimizzi,2017

Tamoto,2014

Igami ,2009

Kondo ,2004

Jong ,2012

Munoz ,2002

Mizuno ,2020
TE seTE

$\begin{array}{rr}0.54 & 0.2686 \\ -0.09 & 0.3201 \\ -0.43 & 0.5553 \\ 0.60 & 0.2167 \\ 0.25 & 0.5902 \\ -0.06 & 0.1921 \\ 0.47 & 0.5685 \\ 0.48 & 0.1003\end{array}$

Hazard Ratio

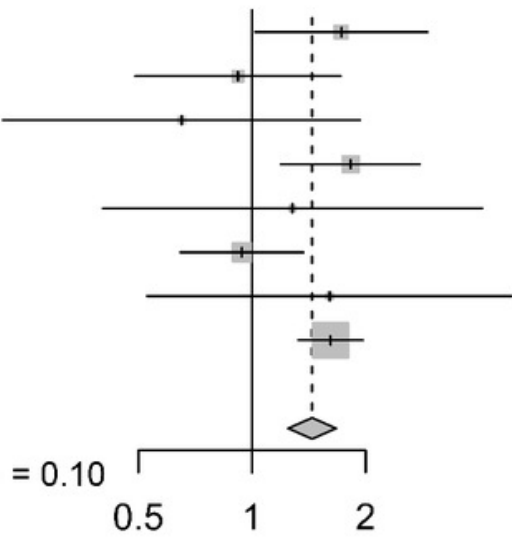

$\begin{array}{lll}0.5 & 1 & 2\end{array}$
HR $\quad 95 \%-\mathrm{Cl}$ Weight

$1.72[1.02 ; 2.92] \quad 7.7 \%$

$0.92[0.49 ; 1.72] \quad 5.4 \%$

$0.65[0.22 ; 1.93] \quad 1.8 \%$

$1.82[1.19 ; 2.79] \quad 11.8 \%$

$1.28[0.40 ; 4.07] \quad 1.6 \%$

$0.94[0.65 ; 1.37] \quad 15.0 \%$

$1.61[0.53 ; 4.89] \quad 1.7 \%$

$1.61[1.33 ; 1.96] \quad 55.0 \%$

$1.44[1.25 ; 1.67] 100.0 \%$

B

\section{Fixed effect mode}

Heterogeneity: $I^{2}=41 \%, \tau^{2}=0.0421, p=0.10$

VR No VR Mean Difference Mean Difference

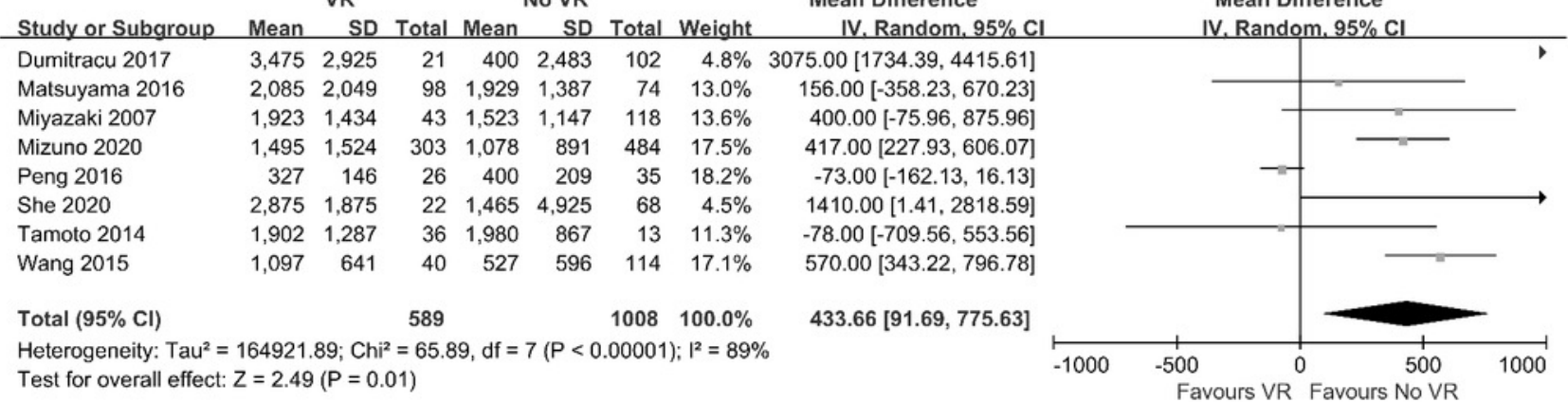

C

VR No VR Odds Ratio

Odds Ratio

Study or Subgroup Events Total Events Total Weight M-H, Random. 95\% Cl $\quad$ M-H. Random, $95 \% \mathrm{Cl}$ $\begin{array}{llllllll}\text { Ebata } 2003 & 52 & 52 & 20 & 108 & 13.2 \% & 453.29 & {[26.85,7651.41]}\end{array}$ Hoffmann $2015 \quad 10 \quad 21 \quad 20 \quad 39 \quad 22.0 \% \quad 0.86[0.30,2.50]$ Schimizzi $2017 \quad 9 \quad 15 \quad 22 \quad 150 \quad 21.7 \% \quad 8.73[2.83,26.95]$ She 2020

Tamoto 2014

$\begin{array}{lllll}15 & 22 & 34 & 67 & 22.2 \%\end{array}$

$2.08[0.75,5.75]$

$2.00[0.55,7.31]$

Total $(95 \% \mathrm{Cl})$

146

$377 \quad 100.0 \%$

$4.72[1.05,21.12]$

\section{Total events}

$106 \quad 101$

Heterogeneity: $\mathrm{Tau}^{2}=2.36 ; \mathrm{Chi}^{2}=27.20, \mathrm{df}=4(\mathrm{P}<0.0001) ; \mathrm{I}^{2}=85 \%$

Test for overall effect: $Z=2.03(P=0.04)$

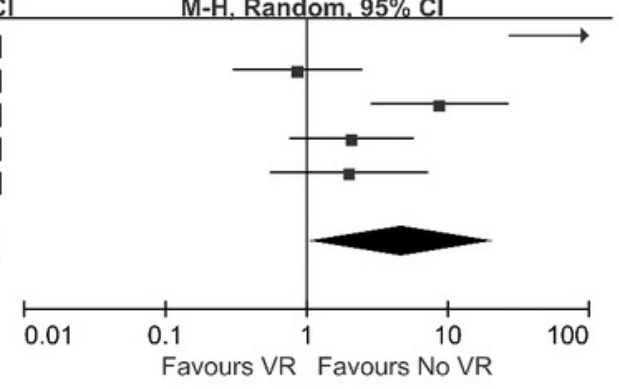

D

\begin{tabular}{lrrrrrr} 
& \multicolumn{9}{c}{ VR } & \multicolumn{1}{c}{ No VR } & Odds Ratio \\
Study or Subgroup & Events & Total & Events & Total & Weight & M-H. Fixed. 95\% C \\
\hline Ebata 2003 & 25 & 52 & 47 & 108 & $28.9 \%$ & $1.20[0.62,2.33]$ \\
Hoffmann 2015 & 9 & 21 & 4 & 39 & $2.9 \%$ & $6.56[1.70,25.26]$ \\
Jong 2012 & 25 & 51 & 57 & 173 & $24.1 \%$ & $1.96[1.04,3.69]$ \\
Matsuyama 2016 & 62 & 98 & 21 & 74 & $16.0 \%$ & $4.35[2.27,8.34]$ \\
Miyazaki 2007 & 38 & 43 & 102 & 118 & $11.6 \%$ & $1.19[0.41,3.48]$ \\
She 2020 & 9 & 22 & 19 & 68 & $10.0 \%$ & $1.79[0.66,4.86]$ \\
Tamoto 2014 & 11 & 36 & 0 & 13 & $0.9 \%$ & $12.18[0.67,222.91]$ \\
Yu 2017 & 7 & 19 & 12 & 76 & $5.5 \%$ & $3.11[1.02,9.51]$ \\
& & & & & & \\
Total (95\% Cl) & & 342 & & 669 & $100.0 \%$ & $2.31[1.70,3.13]$ \\
Total events & 186 & & 262 & & &
\end{tabular}

Heterogeneity: $\mathrm{Chi}^{2}=13.16, \mathrm{df}=7(P=0.07) ; \mathrm{I}^{2}=47 \%$

Test for overall effect: $Z=5.40(P<0.00001)$

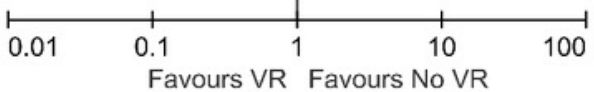


Figure 7

Meta-analysis of studies on lymph node metastasis.

(A) lymph node metastasis rate in patients with and without VR; (B) lymph node metastasis rate in patients with and without PVR; $(C)$ lymph node metastasis rate in patients with and without HAR. 


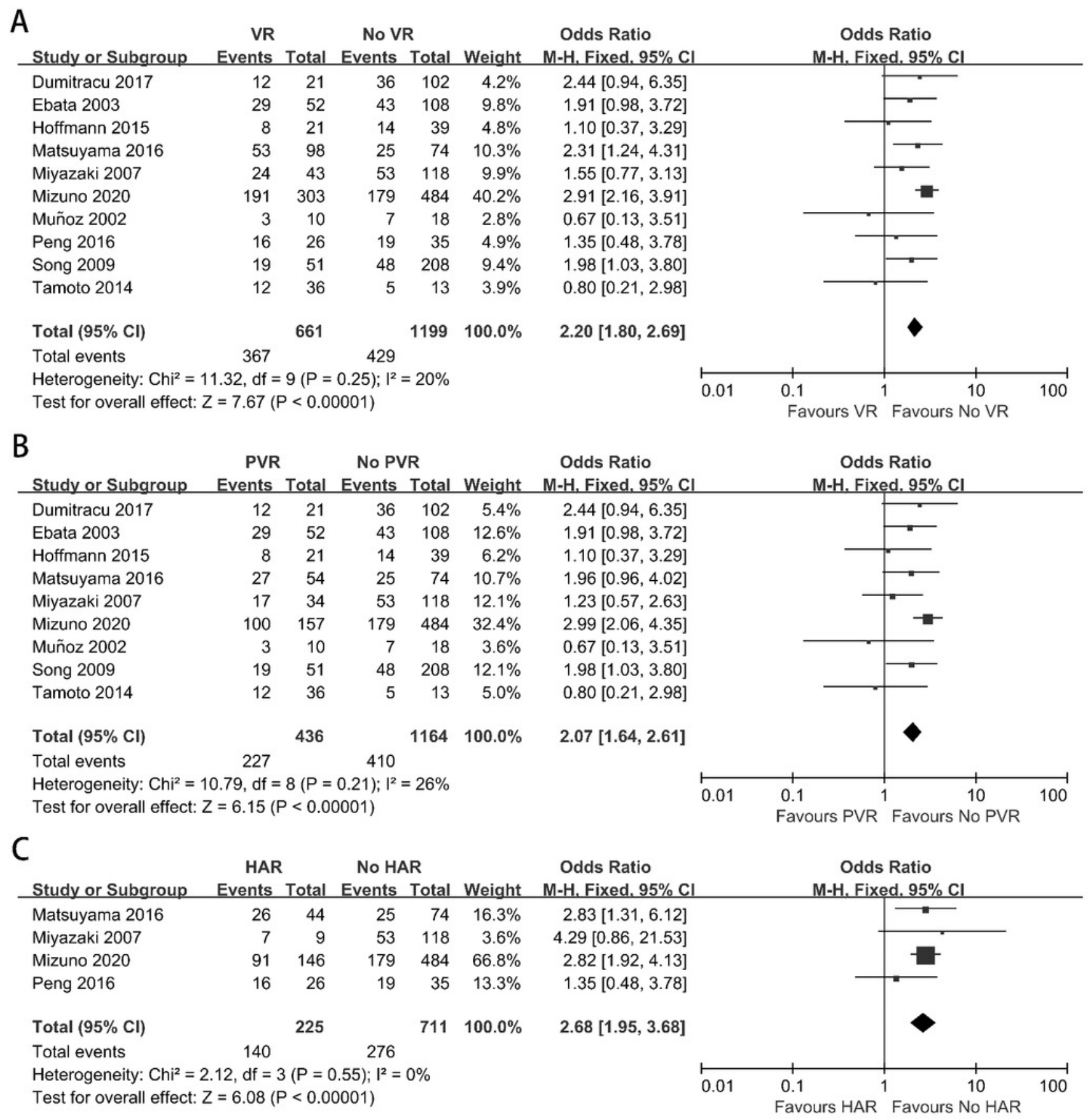

